Canadian

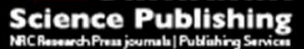

Canadian Journal of Civil Engineering Revue canadienne de génie civil

\title{
A comparison of two-dimensional and three-dimensional flow structures over artificial pool-riffle sequences
}

\begin{tabular}{|r|l|}
\hline Journal: & Canadian Journal of Civil Engineering \\
\hline Manuscript ID & cjce-2017-0274.R1 \\
\hline Manuscript Type: & Article \\
\hline Date Submitted by the Author: & 20-Jul-2017 \\
\hline $\begin{array}{r}\text { Complete List of Authors: } \\
\begin{array}{r}\text { Is the invited manuscript for } \\
\text { consideration in a Special } \\
\text { Issue? : }\end{array}\end{array}$ & $\begin{array}{l}\text { Fazel Najafabadi, Elham; Isfahan University of Technology } \\
\text { Engineering University of Northern British Columbia, Environmental }\end{array}$ \\
\hline Keyword: & $\begin{array}{l}\text { accelerating flow, decelerating flow, pool riffle sequence, secondary } \\
\text { current, shear stress }\end{array}$ \\
\hline
\end{tabular}




\section{A comparison of two-dimensional and three-dimensional flow structures over artificial pool-riffle sequences}

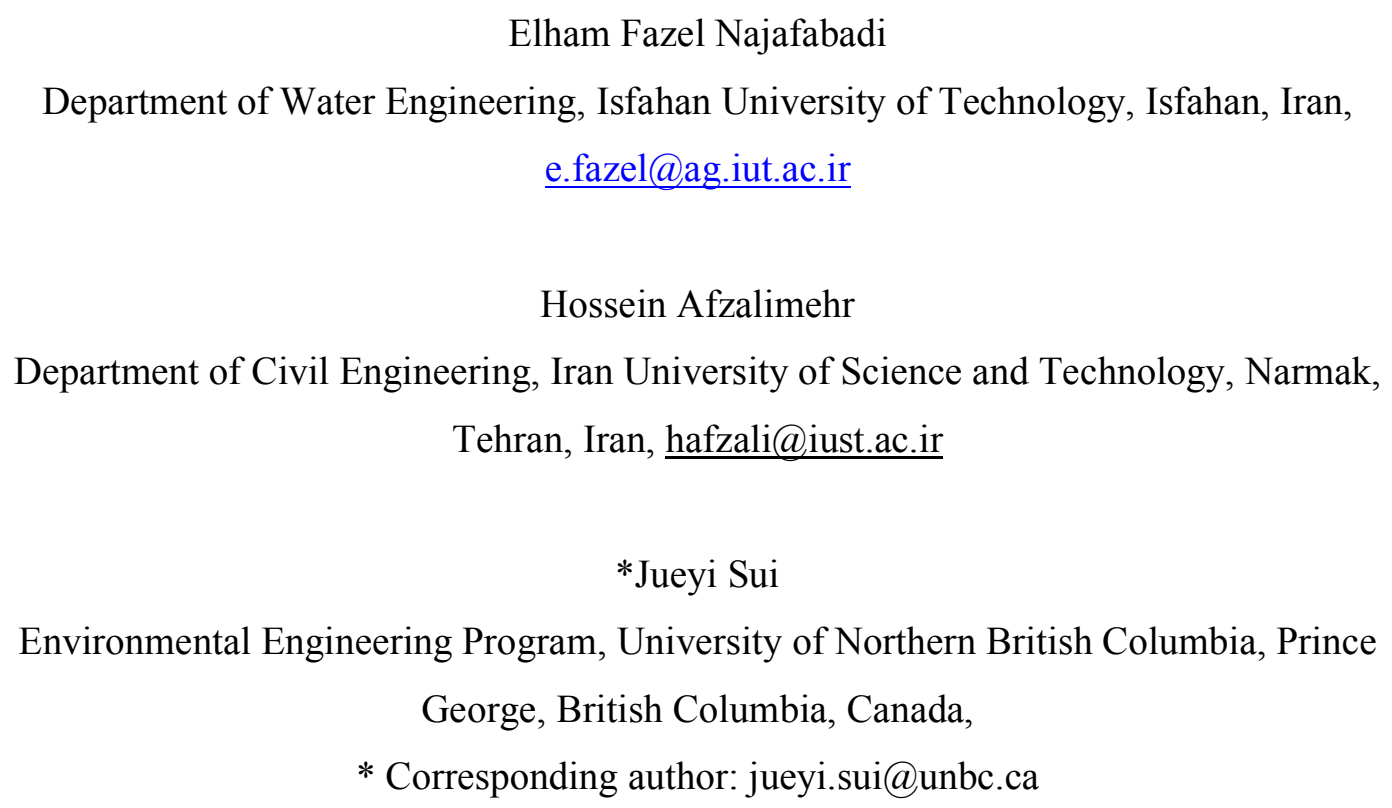

Keywords: accelerating flow, decelerating flow, pool riffle sequence, secondary current, shear stress. 


\section{Introduction}

Although the pool-riffle sequence has been widely studied by many researchers, several key aspects of pool-riffle bed form have not been investigated, such as the $3 \mathrm{D}$ flow structures over pool-riffle sequences. Both pools and riffles are three dimensional bed forms. These bed forms have been resulted as the stream flow structure alternates from areas of relatively shallow to deeper water. As a consequence, the interactions with three-dimensional flow and complex patterns of sediment transport lead to the formation of the pool-riffle sequence. Furthermore, pools and riffles are usually not well defined, resulting in the possible discrepancies between experimental studies and what actually exists in the field.

Up to date, researchers have investigated some important hydrodynamic processes including the reverse relationship between flow velocity near channel bed and the stage (Keller 1971; Clifford and Richards 1992), the generation of turbulent vortices (Hassan and Woodsmith 2004; Thompson 2002, 2006, 2007), and the lateral convergence and divergence of flow (Booker et al. 2001; MacWilliams et al. 2006; Sawyer et al. 2010) with associated phase shifts in shear stress (Wilkinson et al. 2004). As claimed by Clifford and Richards (1992) and Thompson et al. (1996), the flow convergence and divergence normally occur in the pool head section and pool tail section, respectively. Hassan and Woodsmith (2004) pointed out that sediment particles tend to be delivered with lower shear stresses in the pool than those in other channel sections. Clifford (1996) observed that the pool head section has higher turbulence intensity. Thompson $(2002,2004)$ found a shear zone at the downstream section of the obstruction in a forced pool which tends to generate turbulent vortices that may also be important for pool scour (Thompson 2006, 2007). In a pool-riffle sequence which is forced to get formed by a fallen tree, at the bankful discharge, MacVicar and Roy (2007a, 2007b) presented a reverse relationship between the near-bed flow velocity and stage, turbulent vortices and lateral convergence and divergence of flow. Their results indicate that multiple processes may occur simultaneously (MacWilliams et al. 2006; Thompson and Wohl 2009).

To link research results based on field measurements with concepts of hydraulics of open channels, experimental study in laboratory is an useful method for investigating the influence of a non-uniform channel boundary on the distribution of mean flow and turbulence. As we known, characteristic vertical profiles of both flow velocity and Reynolds stress develop due to a balance between the driving force caused by gravity and the resistance force resulted from the channel bed and channel walls. Flow depth in a pool will first increase and then 
decrease from the pool head to pool tail, and thus, it leads to a decelerating flow (DF) with a positive pressure gradient, followed by an accelerating flow (AF) with a negative pressure gradient. The inertial effect of flow showed that, in the outer flow zone farther away from the channel bed, flow velocity in the stream-wise direction remains relatively high in the DF section and relatively low in the AF section (Coles 1956; Perry and Joubert 1963; Kironoto and Graf 1995; Song and Chiew 2001; Yang and Chow 2008).

Imbalances between the production and dissipation of turbulence far away from the boundary lead the distribution of turbulence to have different patterns in non-uniform channels (Best and Kostaschuk 2002; Blanckaert 2009; Van Balen et al. 2009). The Reynolds stress, which is a criterion for assessing the turbulent exchange of momentum, tends to increase above the channel bed in the DF section compared to that for uniform flow due to the production of new turbulence; and decrease in the AF section due to the suppression of turbulence (Kironoto and Graf 1995; Krogstad and Skåre 1995; Warnack and Fernholz 1998; Song and Chiew 2001; Yang and Chow 2008; Lee and Sung 2009; Lee et al. 2010).

Einstein and Shen (1964) demonstrated that a meandering thalweg has been generated on the bed of a straight laboratory channel. Einstein and Shen (1964) claimed this meandering thalweg has been formed by the action of twin surface convergent cells of secondary flow, induced purely by wall turbulence. The appearance of the cellular secondary flow may cause lateral sediment transport, which can in turn enhance and maintain longitudinal bedforms (Karcz 1966; Nezu et al. 1988). Müller and Studerus (1979) reported that up-flows occur over the smooth strips and down-flows over the rough strips forming a pair of counter-rotating flow cells with a diameter which is the same as the flow depth. Nezu and Nakagawa (1984) carried out experiments over artificial longitudinal ridges of $45^{\circ}$ trapezoidal cross-section. They found a pair of counter-rotating flow cells, the up-flows occurred over the ridge and down-flows over the trough. Experimental studies in laboratory regarding cellular secondary flows have also been conducted by Wang et al. (2003 and 2004) and Wang and Cheng (2005), among the others. Onitsuka and Nezu (2001) found that the established fluid movements and the associated sediment transport occurred alternatively on movable plane sand. They also claimed that the cells of secondary-currents became stable in the entire cross section, and this lead to the formation of sand ridges. Wang and Cheng (2006) conducted experiments in laboratory with six artificial rigid bed forms including alternate bed strips with different roughness heights. Wang and Cheng (2006) found that down-flow occurred 
102 over rough strip or trough whereas up-flow occurred over smooth strip or ridge. Their results 103 suggested that the time-mean secondary flows could be reasonably described by simple analytical expressions in the sinusoidal form, which could be applied for various secondary flow structures with different patterns.

Bed forms are defined by changes in bed elevation that will produce accelerating, decelerating and more uniform sections (Radhakrishnan et al. 2006). Over dunes, steps and bumps, transitions between three mentioned sections commonly are characterized by flow separation and reattachment point of the boundary layer (Best 2005). Some researchers claimed that in macro scale pools, bed gradients were normally milder and a fully developed flow separation was not expected to occur (Carling and Orr 2000; MacVicar and Roy 2007b, MacVicar and Rennie 2012).

Most researchers focused their research work on the pool-riffle morphology based either on one-dimensional or two-dimensional flows, ignoring the effect of lateral variability in nonuniform open channels; such as, over dunes (Best and Kostaschuk 2002; Venditti 2007; Macvicar and Rennie 2012), over bumps (Webster et al. 1996) and in numerical studies (Grigoriadis et al. 2009; Lee et al. 2010), to mention only a few. Since lateral and vertical variability of flow characteristics play a very important role in the evolution of a pool-riffle sequence in nature, the existing pool hydrodynamics based on either one-dimensional or twodimensional flows remains unclear.

Along a river reach with a natural pool-riffle sequence, channel width changes; lateral bars may appear; channel sinuosity exists; bed particles get delivered, etc. A lot of aspects regarding the pool-riffle sequence need to be further investigated. In present study, the objectives are (1) to determine whether or not the convergence of lateral flow exists, and if the increased turbulence appears in the simplified pool-riffle sequence morphology; (2) to investigate variations in near-bed shear stress over the pool-riffle sequence; (3) to study the characteristics of the secondary flows along a river reach with pool-riffle sequence.

\section{Experiment setup}

134 Experiments have been carried out in a rectangular flume that is $16 \mathrm{~m}$ long, $0.9 \mathrm{~m}$ wide and $1350.6 \mathrm{~m}$ deep in the hydraulic laboratory, Isfahan University of Technology, Iran. The channel 
136 bed and sidewalls of the flume were made of glass, and the flume bed is horizontal with the 137 bed slope of zero. A tailgate located at the end of the flume was used to control water level 138 during experiments. Flow depths were measured by using a point gauge with $1 \mathrm{~mm}$ increment. 139 A pump with a maximum discharge of 50Liter/s (with the accuracy of $\% \pm 0.5$ ) was used to 140 circulate water from a sump. The flow discharge was measured by an electromagnetic flow 141 meter. The normal flow depth of $0.26 \mathrm{~cm}$ in the channel, measured before bed forms when 142 channel-bed slope is zero and the corresponding width-depth ratio (aspect ratio) was 3.5. 143 Flow conditions have been chosen in such a way to compare our results to those of other 144 studies. The median diameter of sediment $\left(\mathrm{d}_{50}\right)$ was $10 \mathrm{~mm}$ with the geometric standard 145 deviation $\sigma_{\mathrm{g}}=\left(\mathrm{d}_{84} / \mathrm{d}_{16}\right)^{0.5}$ of 1.14 , where $\mathrm{d}_{84}$ and $\mathrm{d}_{16}$ are $84 \%$ and $16 \%$ finer particle diameters, 146 respectively. To compare our results to those of existing research works (e.g., Fazlollahi et al. 147 2015b), sediment grain size in our study was similar to those of others. The flexible carton148 plast sheets were used to shape the channel bed. Then, gravel grains were attached to the 149 channel bed. The gravel grains were flattened by applying pressure on carton-plast sheets to 150 eliminate large scale variations of bed form topography. The channel section of a riffle-pool151 riffle sequence started at the cross section $9.5 \mathrm{~m}$ downstream from the flume entrance. To 152 compare our results to those of other researchers, dimensions of bed form in our study have 153 been decided based on the existing studies (e.g. Fazlollahi et al. 2015b; MacVicar and Rennie 154 2012). The wavelength of the artificial bed form sequence was $2 \mathrm{~m}$ from the upstream wave155 crest to the downstream wave-crest. In the stream wise direction, both entrance slope and exit 156 slope of the pool were constructed with a slope of $15^{\circ}$. Flow depth changes along the 157 following 5 sections, namely, flow depth above the upstream wave-crest was shallow, then 158 increased along the entrance slope of pool, increased to a constant of deepest in the middle of 159 the pool, decreased along the exit slope of pool and then became the shallowest over 160 downstream wave-crest. In total, 22 cross sections for measurements have been set up along 161 this riffle-pool-riffle sequence. The spacing distance between adjacent cross sections was 10 $162 \mathrm{~cm}$. Data collections have been conducted at these 22 cross sections for all experimental runs. 163 In present research, as shown in Figure 1a and Figure 1b, two types of bedform were used to represent two-dimensional and three-dimensional pool-riffle sequences, respectively. For the 2D pool-riffle sequence, two profiles were measured at each cross section, one profile was measured at the center of channel and another one located at a distance of $20 \mathrm{~cm}$ from the left channel wall of channel. However, for the 3D pool-riffle sequence, the thalweg was centered along pool-riffle sequence. In addition to collecting data along the central axis (thalweg), data were also collected along other three lines which were located at a distance of $10 \mathrm{~cm}, 20 \mathrm{~cm}$ 
170 and $30 \mathrm{~cm}$ from the left channel wall, respectively. Therefore, along each longitudinal axis, 22

171 profiles were obtained, as shown in Figure 1c. For each bed form with different geometries, 172 experiments have been carried out with following three discharges, $21.4 \mathrm{~L} / \mathrm{s}, 25 \mathrm{~L} / \mathrm{s}$ and $30 \mathrm{~L} / \mathrm{s}$.

173 However, due to space limitation, only research results under flow condition with the maximum discharge $(30 \mathrm{Lit} / \mathrm{s})$ are presented in this study.

175

176

177

In this experimental study, a period of two-minutes for data collection has been set up. Threedimensional velocity components were recorded using a downward looking 3D Acoustic Doppler Velocimeter with a frequency of $200 \mathrm{~Hz}$. The down looking ADV sensor is equipment which is able to use to collect data near the bed (for example, $3 \mathrm{~mm}$ near the bed, depending on the sampling volume selection). However, the down looking ADV device is unable to collect data in the zone from water surface to a depth of $5 \mathrm{~cm}$ below water surface. Measured data showed that there is no difference between results using 2-minutes data sampling and those using 5-minutes data sampling. Velocity spikes were removed using the phase-space despiking algorithm in the free software package WinADV (Goring and Nikora 2002). Velocity profiles were visually inspected to remove improper data. Sometimes, improper data occurred near the rough bed where minor variations in gravel position and location might affect signal quality for collecting data, especially about $10 \mathrm{~cm}$ from the boundary, where the reflectance from the bed contained poor quality data series (MacVicar and Rennie 2012). The pool-riffle morphology used in present experiments was measured by using a ruler, with the accuracy of $\pm 1 \mathrm{~mm}$, installed on the frame which was set up at tracks above the flume.

\section{Theoretical background}

\subsection{Statistical description of velocity and turbulence}

Instantaneous velocity in the stream-wise $(u)$, lateral $(v)$, and vertical $(w)$ directions were decomposed into time-averaged components $(\bar{u}, \bar{v}, \bar{w})$ and turbulent components $\left(u^{\prime}, v^{\prime}, w^{\prime}\right)$ :

$$
u=\bar{u}+u^{\prime} \quad v=\bar{v}+v^{\prime} \quad w=\bar{w}+w^{\prime}
$$

In the zone close to the channel bed (i.e., the inner zone), the stream-wise velocity follows the law of the wall, and can be written as following (Mac vicar and Rennie 2012): 
$203 \quad \frac{u}{u^{*}}=\frac{1}{\kappa} \ln \left(\frac{z}{z_{0}}\right)$

Where, $u^{*}$ is the shear velocity, $\kappa$ is the von Karman coefficient $(\kappa=0.4), z$ is the height above the bed, and $z_{o}$ is the reference bed level $\left(z_{o}=d_{50}\right)$. In this study, the calculated shear velocity by means of the wall law is named $u_{i n}^{*}$.

Equation 2 is a universal equation. As pointed out by White (1991) that Equation (2) is independent of the pressure gradient. Therefore, changes of flow condition due to changes in geometric conditions do not affect the validity of this universal law. In addition, as stated Barenblatt (1982) that this law is an empirical law and its validity does not justify any theoretical base for its development.

The important component of Reynolds stress was calculated from turbulent fluctuations in the stream-wise and vertical directions:

$$
\tau_{R}=-\rho \overline{u^{\prime} w^{\prime}}
$$

where, $\rho$ is the fluid density. The Reynolds stress at the bed $\left(\tau_{R}\right)$ was estimated at the bed reference level from the shear stress profile which is the output of WinADV. This gave a second estimate of the shear velocity $\left(u_{R}^{*}=\sqrt{\tau_{R} / \rho}\right)$. This method, sometimes, is sensitive to measurement errors due to steep gradients in Reynolds stress in non-uniform flow at the bed (Song and Chiew, 2001; Yang and Chow, 2008). Also, shear stress was estimated from a calibrated relation with the turbulent kinetic energy (MacVicar and Rennie 2012):

$$
\tau_{\text {tke }}=0.5 \rho c_{2}\left(\overline{u^{\prime 2}}+\overline{v^{\prime 2}}+\overline{w^{\prime 2}}\right)
$$

where, $c_{2}$ is a constant with an approximately value of 0.2 . From Equation 4 , the shear velocity can be also estimated as $u_{t k e}^{*}=\sqrt{\tau_{t k e} / \rho}$. As pointed out by Biron et al. (2004), this method was recommended for the complex flows because it does not assume a particular shape for the velocity profile. This method is similar to Reynolds stress method $\left(u_{R}^{*}\right)$, using turbulent fluctuations, however, $u_{t k e}^{*}$ applies all three velocity components in the stream-wise, lateral, and vertical directions.

\subsection{Secondary flow mechanism}


233 The characteristics of secondary flows are hard to obtain because they easily fluctuate and 234 change under different flow conditions. Therefore, a coefficient can be used to describe the rotational direction and the intensity of the secondary flows. All three components of velocity vector change along the vertical axis and the maximum value of stream wise velocity component often appears below the free surface because of the dip phenomenon due to the influence of the secondary currents (Yang et al. 2004). All three velocity components can be used to effectively represent secondary flow. It is assumed that all components could be expressed, in terms of the depth-averaged stream wise velocity $\left(U_{d}\right)$, as following:

$$
u=m_{1} U_{d}, \quad v=m_{2} U_{d}, \quad w=m_{3} U_{d}
$$

242 or

$$
m_{1}=\frac{u}{U_{d}}, \quad m_{2}=\frac{v}{U_{d}}, \quad m_{3}=\frac{w}{U_{d}}
$$

where, $m_{1}, m_{2}$ and $m_{3}$ are dimensionless coefficients. Then, the product of each couple velocity components can be expressed as follows:

$$
u v=m_{1} m_{2} U_{d}^{2} \quad v w=m_{2} m_{3} U_{d}^{2} \quad u w=m_{1} m_{3} U_{d}^{2}
$$

247 By integrating each part of Equation 7 from zero to the maximum measured depth $(\mathrm{H})$, the 248 depth-averaged of $u v, v w$ and $u w$ can be obtained as follows:

$$
\begin{aligned}
& (u v)_{d}=\frac{1}{H} \int_{0}^{H} u v d z=\left[\frac{1}{H} \int_{0}^{H} m_{1} m_{2} d z\right] U_{d}^{2}=M_{12} U_{d}^{2} \\
& (v w)_{d}=\frac{1}{H} \int_{0}^{H} v w d z=\left[\frac{1}{H} \int_{0}^{H} m_{2} m_{3} d z\right] U_{d}^{2}=M_{23} U_{d}^{2} \\
& (u w)_{d}=\frac{1}{H} \int_{0}^{H} u w d z=\left[\frac{1}{H} \int_{0}^{H} m_{1} m_{3} d z\right] U_{d}^{2}=M_{13} U_{d}^{2}
\end{aligned}
$$

where, $M_{12}, M_{23}$ and $M_{13}$ are defined as the secondary flow coefficients:

$$
M_{12}=\frac{(u v)_{d}}{U_{d}^{2}} \quad M_{23}=\frac{(v w)_{d}}{U_{d}^{2}} \quad M_{13}=\frac{(u w)_{d}}{U_{d}^{2}}
$$

\subsection{Basic equation for production term of secondary currents}

The turbulence induced by secondary currents in an open channel flow is explained well by the longitudinal vorticity equation. The distribution of the velocity difference $\left(v^{2}-w^{2}\right)$ plays an essentially important role, as was pointed out by Einstein and Li (1958). The differences in secondary currents can be explained by the difference of the $\left(v^{\prime 2}-w^{\prime 2}\right)$ distribution, in the 
259 following way. The longitudinal vorticity equation in a fully-developed turbulent flow is 260 given as follows:

261

$$
v \frac{\partial \xi}{\partial y}+w \frac{\partial \xi}{\partial z}=\frac{\partial^{2}}{\partial y \partial z}\left(v^{\prime 2}-w^{\prime 2}\right)-\left(\frac{\partial^{2}}{\partial y^{2}}-\frac{\partial^{2}}{\partial z^{2}}\right) \overline{v^{\prime} w^{\prime}}+v\left(\frac{\partial^{2} \xi}{\partial y^{2}}+\frac{\partial^{2} \xi}{\partial z^{2}}\right)
$$

262

where, $\xi=\partial w / \partial y-\partial v / \partial z$. The last term of in Equation 10, the viscous term, is neglected except very near the wall. The convection term of the left-hand side can be approximately neglected, according to the examination of Nezu and Nakagawa (1984). The Reynolds shear stress $-\overline{v^{\prime} w^{\prime}}$ can be expressed using the eddy viscosity model as follows:

$$
-\overline{v^{\prime} w^{\prime}}=\varepsilon_{y z}\left(\frac{\partial w}{\partial y}+\frac{\partial v}{\partial z}\right)
$$

where, $\varepsilon_{y z}$ is the eddy viscosity coefficient. Then, the secondary current velocity components $v$ and $w$ are expressed using stream function $\psi$ as follows:

$$
v=-\frac{\partial \psi}{\partial z}, \quad w=\frac{\partial \psi}{\partial y}
$$

Substituting Equations 11 and 12 into Equation 10, the following equation can be obtained:

$$
\left(\frac{\partial^{2}}{\partial y^{2}}-\frac{\partial^{2}}{\partial z^{2}}\right) \varepsilon_{y z}\left(\frac{\partial^{2} \psi}{\partial y^{2}}+\frac{\partial^{2} \psi}{\partial z^{2}}\right)+v\left(\frac{\partial^{4} \psi}{\partial z^{4}}+2 \frac{\partial^{4} \psi}{\partial y^{2} \partial z^{2}}+\frac{\partial^{4} \psi}{\partial y^{4}}\right)=\frac{\partial^{2}}{\partial y \partial z}\left(v^{\prime 2}-w^{\prime 2}\right)
$$

$\varepsilon_{y z}$ remains unknown, since it is quite difficult to determine $-\overline{v^{\prime} w^{\prime}}$ in open channel flows. Therefore, the distribution of $\varepsilon_{y z}$ is assumed to be given as a parabolic function. It is the distribution of $\left(v^{\prime 2}-w^{2}\right)$ that controls the structure of the secondary currents, as pointed out by Gerard (1978).

\section{Results and discussions}

\subsection{Stream-wise velocity}

In the constructed pool riffle sequence, the velocity distribution changes as a result of accelerating flow (AF) and decelerating flow (DF). Figures 2a-2d displayed the velocity profiles along the longitudinal lines with a distance of $10 \mathrm{~cm}, 20 \mathrm{~cm}, 30 \mathrm{~cm}$ and $45 \mathrm{~cm}$ from left channel wall of the 3D pool riffle sequence (facing downstream), respectively. Along all these four longitudinal lines, the near-bed velocity decreases along the convective deceleration flow (CDF) section as flow depth increases. Also along all these four 
288 longitudinal lines, near-bed velocity is relatively high along the convective acceleration flow 289 (CAF) section as flow depth decreases. Results showed that, velocities near channel bed 290 along the central line for the 2D pool riffle sequence (Figure 2e) are larger than those for 3D 291 pool riffle sequence (Figure 2d) in all parts. Also, for 2D pool riffle sequence, the near-bed 292 velocities decreased along the decelerating flow (DF) section, similar to that for the 3D pool 293 riffle sequence.

Flow separation did not occur along the longitudinal line of $10 \mathrm{~cm}$ which is the closest to the channel wall, but separation zone appeared with increasing distance from the channel wall. For the longitudinal line of $20 \mathrm{~cm}$ away from the channel wall, flow separation started at the decelerating flow section. For the longitudinal line of $30 \mathrm{~cm}$ away from the channel wall, flow separation started from the upstream riffle, and was extended to the beginning deepest part of the pool. However, for the longitudinal line of $30 \mathrm{~cm}$ away from the channel wall, the separation zone develops and covered one-half of the deepest part of the pool. Whiles along the central longitudinal line of the pool riffle sequence ( $45 \mathrm{~cm}$ away from channel wall), and the area of flow separation zone decreased and was almost limited to the channel section from the end of the entrance slope to the middle of the deepest part of the pool, with a distance of $120 \mathrm{~cm}$ from the beginning part of the upstream riffle. In contrast of all mentioned above, along the central line of the 2D pool riffle sequence, there is a small separation zone started near the end of entrance slope, and disappeared in the deepest part of the middle of the pool.

Despite the differences in shear velocities estimated from the slope of velocity gradient in the inner layer $\left(u_{i n}^{*}\right)$, generally, shear velocity decreases in the DF section, and increases as flow depth decreases (AF section) along all longitudinal lines with different distances from the channel wall (Figure 2f). Results indicated that, with the exception of the longitudinal line of $20 \mathrm{~cm}$ away from the channel wall, the $u_{i n}^{*}$ trend along other longitudinal lines was nearly symmetric to the middle point of the pool, which would indicate that shear velocity is mainly a function of flow depth. This finding is in accordance of the research work performed by MacVicar and Rennie (2012), however, their research result was only along the central axis of the channel. Results showed that, along the longitudinal lines of $30 \mathrm{~cm}$ and $45 \mathrm{~cm}$ away from the channel wall, shear velocities in the AF section are greater than the corresponding 
321 section is greater than that in the DF section. Along the longitudinal lines of $10 \mathrm{~cm}$ and $20 \mathrm{~cm}$ 322 away from the channel wall, however, trends of velocity values were not similar to those of along the longitudinal lines of $30 \mathrm{~cm}$ and $45 \mathrm{~cm}$ away from the channel wall. It is found that, along the longitudinal lines of $10 \mathrm{~cm}$ and $20 \mathrm{~cm}$ away from the channel wall, there were little differences between shear velocities in the AF section and those in the DF section.

\subsection{Turbulence along the channel central line}

Due to the presence of bed form as pool riffle sequence, it resulted in the CAF and CDF in the channel. Thus, the shape of Reynolds shear stress profiles deviated from the shape of Reynolds shear stress profiles for uniform flow, as showed in Figures 3a-3e. For both 2D pool riffle sequence and 3D pool riffle sequence, when the distance from the start upstream riffle (x) is in the range of $20-50 \mathrm{~cm}$, under condition of normal flow, shear stress is typically highest near the bed surface and linearly approaches zero at the water surface, as is expected in uniform flow (Nezu and Nakagawa 1993). For the 3D pool riffle sequence, however, with approaching to the channel wall, shear stress profiles were more deformed than those for uniform flow. The presence of strong secondary flow and cross currents might be responsible for this deformed shear stress profiles. For both the 3D pool riffle sequence and the 2D pool riffle sequence, and for all distances from the channel wall, along the entrance slope of the pool, the maximum Reynolds shear stress occurs at a large distance away from the bed surface. This effect occurs in the CDF due to positive stream-wise pressure gradients that leads to increased shear (Krogstad and Skåre 1995; Yang and Chow 2008; Lee et al. 2010). For the 3D pool riffle sequence, the magnitude of Reynolds shear stress is the highest at the CDF section along the longitudinal lines of both $10 \mathrm{~cm}$ and $20 \mathrm{~cm}$ from the channel wall, as shown in Figures 3a and 3b. However, along other two longitudinal lines of $30 \mathrm{~cm}$ and $45 \mathrm{~cm}$ (central line) away from the channel wall for the 3D pool riffle sequence, and also along the channel central line for 2D bed form, the highest shear stress is moved toward the middle of pool (Figures 3c, 3d and 3e, respectively). At the end of the exit slope of pool, although the shear stress profile is still affected from CAF section, the distribution of shear stress at the downstream of the pool tends toward the distribution observed at the upstream limit of the pool. 
353 The shear velocity at the reference bed level $\left(u_{R}^{*}\right)$ estimated from Reynolds shear stress 354 displays similar trends to $u_{i n}^{*}$, as shown in Figure $3 \mathrm{f}$. In general, $u_{R}^{*}$ decreases in the CDF 355 section, approaches a minimum in the middle of the pool, and increases in the CAF section. It 356 is noteworthy that only along the longitudinal lines of $30 \mathrm{~cm}$ away from the channel wall, $u_{R}^{*}$ 357 is greater in CDF section than that in CAF section. Along all other longitudinal lines, there is 358 a reverse trend. However these differences are small along other longitudinal lines. These results aren't consonant to the $u_{i n}^{*}$ results; as along the longitudinal lines of $30 \mathrm{~cm}$ and $45 \mathrm{~cm}$ away from the channel wall, the shear velocities $\left(u_{i n}^{*}\right)$ are higher along the exit slope of the pool comparing to those along the upstream slope of the pool. However, there are reverse results along other longitudinal lines. Results indicated that, along the entrance slope of the pool and the pool section, the shear velocities estimated from turbulence is higher than the shear velocities estimated from time-averaged velocities. However, along the exit slope of the pool, the values of $u_{i n}^{*}$ are higher than $u_{R}^{*}$. Along both upstream and downstream riffle sections, along all longitudinal lines, shear velocities estimated from the velocity gradient are higher than those estimated from Reynolds shear stress.

It is not expected that, when flow passes through the pool, the maximum Reynolds stress happen at the bed surface. As shown in Figure 3g, for the 3D pool riffle sequence, the shear velocity was calculated from the maximum Reynolds shear stress in each profile $\left(u_{R \max }^{*}\right)$ along all four longitudinal lines with different distances away from the channel wall. The maximum value of $u_{R \max }^{*}$ was different along different longitudinal lines away from the channel wall. Along the central line, the maximum $u_{R \max }^{*}$ appeared at a distance of $130 \mathrm{~cm}$ from the beginning upstream riffle. With approaching to the channel wall, the location of the maximum $u_{R \max }^{*}$ is moved to the transition from the normal flow to the CDF. However, there are some irregularities along the longitudinal line of $10 \mathrm{~cm}$ away from the channel wall, and despite the irregularities, the higher $u_{R \max }^{*}$ values generally occurred in the middle of pool and the $u_{R \max }^{*}$ values decreased toward both the upstream riffle and downstream riffle. The

381 minimum values of $u_{R \min }^{*}$ along the channel central line, occurred just at the transition from 
382 CAF back to the downstream riffle, while along other three longitudinal lines, the minimum values of $u_{R \min }^{*}$ values occurred at the upstream riffle.

Changes in lateral component of turbulence does not appear in the principal Reynolds shear stress but is included as $v^{\prime 2}$ term in $u_{t k e}^{*}$, as shown in Figure $3 \mathrm{~h}$. The trends of both $u_{R}^{*}$ and $u_{t k e}^{*}$ are similar. Although there are some irregularities in $u_{t k e}^{*}$ values, the lowest $u_{t k e}^{*}$ occurred at the pool. The comparison between $u_{R}^{*}$ and $u_{t k e}^{*}$ along the channel section from the upstream riffle to the middle of exit slope of pool showed that, the values of $u_{t k e}^{*}$ are less than $u_{R}^{*}$ along all four longitudinal lines. Whilst, along the channel section from the middle of pool exit to the downstream riffle, the values of $u_{t k e}^{*}$ are more than $u_{R}^{*}$, along longitudinal lines of $10 \mathrm{~cm}$ and $30 \mathrm{~cm}$ away from the channel wall. It is found that lateral turbulence exchanges are important in these zones. Overall, $u_{t k e}^{*}$ values indicate that shear stresses as a result of threedimensional turbulence are higher than shear stresses calculated from the principal Reynolds stress $\left(u_{R}^{*}\right)$ along the channel section of the final $30 \%$ of pool riffle sequence.

\subsection{Mechanism of the secondary flow}

For the 3D pool riffle sequence, the dimensionless coefficients, $m_{1}, m_{2}$ and $m_{3}$ are calculated for different parts of pool riffle sequences, as the calculation example showed in Figure 4. Results showed that, everywhere along this 3D pool riffle sequence, the dimensionless coefficient $m_{1}$ is dominant and the fluctuation of this coefficient profile is larger than two other dimensionless coefficients. This is expected because the velocity gradient in the stream wise direction is larger than those of along other two directions for velocity components. The dimensionless coefficient $m_{l}$ has the same results along the 2D pool riffle sequence.

Investigation of the products of dimensionless coefficients of $m_{1} m_{2}, m_{2} m_{3}$ and $m_{1} m_{3}$ has been performed for all profiles. Figure 5 showed an example of the products of dimensionless coefficients for the 3D pool riffle sequence. Results of these profiles indicated that, for the $3 \mathrm{D}$ pool riffle sequence, the maximum gradient of $m_{1} m_{2}$ profiles, are larger than those of $m_{2} m_{3}$ and $m_{1} m_{3}$ profiles for almost all sections of the pool riffle sequence (except for entrance slope of pool) and all longitudinal lines away from the left channel wall. It has been proved 
413 that the intensity of the secondary flow is much stronger at the $\mathrm{x}-\mathrm{y}$ surface. Also it has been 414 demonstrated that the changes from the channel bed to the water surface have almost the 415 same trend as those of $m_{2}$. Whereas, except at the upstream riffle, for all other parts of the 2D 416 pool riffle sequence, the product of dimensionless coefficient of $m_{1} m_{3}$ had the largest 417 gradient.

Except for downstream riffle, for all other parts of the 2D pool riffle sequence, results showed an increasing trend in the intensity of secondary currents. It has been noticed that there exists little difference between the trend in the intensity of secondary currents along the $2 \mathrm{D}$ pool riffle sequence and that along the $3 \mathrm{D}$ pool riffle sequence. At the upstream riffle of the 3D pool riffle sequence, in the direction of flow, regular trend for intensity of the secondary flow has not been noticed. However, in the section of the entrance slope of the pool, along all longitudinal lines away from the left channel wall, the intensity of the secondary flow is increased with the highest increase along the longitudinal line of $20 \mathrm{~cm}$ away from the left channel wall. The increase in the intensity of secondary flow is continued to the end of the entrance slope of pool. Then, the intensity of secondary flow decreases in the deep pool along all the longitudinal lines away from the left channel wall, except the longitudinal line of $10 \mathrm{~cm}$. However, the biggest decrease occurs along the longitudinal line of $20 \mathrm{~cm}$ away from the left channel wall. Along the channel section from the end of deep pool to the end of the exit slope, the intensity of secondary flow varies depending on the distance from the channel wall. The intensity of secondary flow is increased along the longitudinal lines of $20 \mathrm{~cm}$ and $30 \mathrm{~cm}$ away from the channel wall, however, it is decreased along the longitudinal lines of $10 \mathrm{~cm}$ and $45 \mathrm{~cm}$ away from the channel wall. Results showed that the decreasing trend is very mild, and increasing trend along the longitudinal line of 20

The "M" value together with its sign has special physical meanings. As pointed out by Liu et al. (2013), the sign and the absolute value of " $\mathrm{M}$ " represents the rotational direction and the intensity of the secondary flows, respectively. Along the central line of the 3D pool riffle sequence, assessment of the absolute values of $\mathrm{M}$ in the stream direction indicated that the values of $M_{13}$ had the largest values than other two coefficients, followed by $M_{12}$ and $M_{23}$, as

446 shown in Figure 6a. By approaching to the channel wall, however, the $\mathrm{M}_{23}$ is remained low; 
447 the difference becomes small for other two coefficients, so that, along the longitudinal line of $44810 \mathrm{~cm}$ away from the left channel wall, the absolute values had nearly the same amounts. 449 Investigation of the $\mathrm{M}_{13}$ absolute values along the channel central line showed that, the 450 intensities in the flow direction along the entrance slope are increased; the intensities in the 451 deep pool are constant and had the highest values; and the intensities in the following exit 452 slope are decreased along the channel, as shown in Figure 6b. By approaching to the channel 453 wall, an obvious trend as mentioned above has not been noticed. Results showed that the 454 intensities are increased but appeared some irregularity.

As showed in Figure 6a, in the decelerating flow section of the 3D pool riffle sequence, the negative $\mathrm{M}_{13}$-values along the channel central line, indicate that the rotational direction of the secondary current cell is counter-clockwise. Therefore, the dominant vertical component of flow is directed toward the channel bed. However, the $\mathrm{M}_{12}$-values had lower values, the negative sign of this coefficient showed the oriented lateral component of flow toward the channel central line, thus the reported convergence of flow by MacVicar and Rennie (2012)

462 is confirmed.

Results showed that, although $\mathrm{M}_{13}$ and $\mathrm{M}_{12}$ are in the order of magnitudes near the channel wall, there are some differences. In the $3 \mathrm{D}$ pool riffle sequence, $\mathrm{M}_{13}$-values are negative, thus, the rotational direction of the secondary current cell is counter-clockwise. It means that the dominant vertical flow is oriented toward the channel bed. However, $\mathrm{M}_{12}$-values are positive, this means that the secondary flow rotates in the direction of clockwise. It is represented that the dominant flow is directed toward the channel wall.

These findings indicated that the divergence of flow is not in agreement with the conceptual model mentioned by MacVicar and Rennie (2012). On the other hand, along the channel central line in the section of accelerating flow, the negative sign of $\mathrm{M}_{13}$-values represented a downward vertical flow, and the positive sign of $\mathrm{M}_{12}$-values indicated an oriented lateral flow toward the channel wall. Therefore, the divergence of flow is confirmed the conceptual model reported by MacVicar and Rennie (2012). Also along the section of accelerating flow, all $\mathrm{M}_{12}$ and $\mathrm{M}_{13}$ values near the channel wall are in the order of magnitudes and positive, representing a clockwise rotating secondary flow and divergent flow in this section of the $3 \mathrm{D}$ 
480 increasing the flow discharge. It means that increase in three-dimensional velocities due to 481 the constant flow depth lead to stronger secondary current cells.

Along the 2D pool riffle sequence, assessment of secondary flow coefficient (M) has been done. Along the decelerating flow section, the values of $\mathrm{M}_{12}$ and $\mathrm{M}_{13}$ had negative sign. The physical meaning of these values demonstrated the counter-clockwise rotational secondary current cell and indicated downward and central line oriented flow, as shown in Figure 6c. Therefore, the convergence of flow occurred in the decelerating flow section (MacVicar and the values of $\mathrm{M}_{12}$ have the positive sign. From a physical point of view, it is showed that the rotational direction of the secondary current cell is counter-clockwise and clockwise for $\mathrm{M}_{13}$ and $\mathrm{M}_{12}$, respectively. These results confirmed the divergent flow reported by MacVicar and Rennie (2012). Also, from the Figure 6c, one can see that along the entire sequence of poorriffle, the maximum intensity of the secondary currents occurred at the middle of pool.

\subsection{Distribution of production term of secondary currents}

Figure 7 illustrated distribution of $\left(v^{\prime 2}-w^{\prime 2}\right)$ for different parts of the 2D pool riffle sequence. Results showed that along the upstream riffle section, the production term of secondary currents has low values near the vertical wall close the water surface. Large values of the production term of secondary currents are found to be located near the center of the channel bed, as showed in Figure 7a. Along the entrance slope of the pool (the decelerating section), a small spot with the low values of $\left(v^{\prime 2}-w^{\prime 2}\right)$ is found near the channel bed, but cross the channel from the left wall to the right. In return, a wide region with the low values of $\left(v^{\prime 2}-w^{\prime 2}\right)$ is diffused at the water surface across the whole channel, as showed in Figure 7b. In the deep pool, a zone with low values of production term of secondary currents is located near the bed, and zones with high values of production term of secondary currents appear near the water surface and close to the channel wall (Figure 7c). Along the channel section from the end of the deep pool to end of the accelerating slope, zones with low values of production term of secondary currents are noticed near channel walls from channel bed to water surface. Zone with high values of production term of secondary currents appears along the channel central line of, as shown in Figure 7d. Along the downstream of riffle, spots with low values of production term of secondary currents move toward the channel central line, in contrast, spots with high values occur near channel walls, especially close to the channel bed (Figure 7e). 
515 Figure 8 displayed the distribution of production term of secondary currents in the 3D pool 516 riffle sequence. Along the section of the upstream riffle, spots with high value of production 517 term of secondary currents are located near the channel bed, very close to the longitudinal 518 line of $20 \mathrm{~cm}$ away from the channel wall, as indicated by Figure 8a. However, the values of 519 this parameter decrease toward the central line of channel and water surface. Once water 520 enters the decelerating section of the 3D pool riffle sequence, zones contain negative and zero 521 values have not been noticed. Ten centimeters after entering the decelerating section, a zone 522 of approximately $10 \mathrm{~cm}$ wide contains negative and zero values is located near the channel 523 central line. This zone has been developed in such a way that the zero values appear from 524 water surface to the channel bed, but the negative values is covered about $2 / 3$ of depth from water surface toward the bed (Figure 8b). However, as shown in Figure 8c, at the boundary between entrance slope and the deep pool, the coverage area with negative and zero values is decreased to a small zone located in the middle flowing water. The high values of production term of secondary currents have been assessed. It is found that, along the decelerating flow section, zones with high values have been developed from the near-bed and near-channel wall toward water surface vertically. By approaching to the end of decelerating flow section, the size of zones with high values decreases.

Along the deep pool section of the 3D pool riffle sequence, zones with low values of production term of secondary currents still remain around the channel central line. These zones with low values are located not only near water surface but also near channel bed, also the size of these zones with low values increases. By approaching to the border between the deep pool section and the accelerating flow section, also the size of these zones with low values decreases. It is also found that, zone with high values of production term of secondary currents is extended near the channel wall. Toward the accelerating flow section of the pool riffle sequence, the size of zone with high values increases and occupies a large portion of flow cross section near water surface (Figure 8d).

At the start of accelerating flow section, the size of zone with low values of production term of secondary currents is expanded nearly throughout the whole water depth around the channel central line. However, along the accelerating slope section, zones with high values production term of secondary currents allocated over a large portion of flow cross section and moved toward the channel central line. In the mean time, zones with low values of the 
548 production term of secondary currents moved toward the vertical walls near the channel bed, 549 as indicated by Figure 8e. This distribution pattern of zones with low values of production term continued to the end of accelerating section. At the border between the end of accelerating section and downstream riffle, two zones with high values of production term are produced. The first zone is located around the channel central axis near water surface centered, and the second one is developed near the channel bed oriented toward the channel wall. By further moving to the downstream riffle, the effect of the zone with high values of production term near the channel bed decreases, and this zone with high values disappears at the last cross section for measurement, as showed in Figure 8f. However, the other zone with high values of production term at the water surface still exists, and the size of this zone becomes small. At the last cross section, a large portion of the cross section is covered by zone with low values of production term. It has been observed that along the downstream riffle, the negative values of production term disappear and the zone with values close to zero occupy a small area.

Assessment of distribution of the zero isoline of $\left(v^{\prime 2}-w^{\prime 2}\right)$ showed that, along the decelerating flow section of the pool-riffle sequence, this zero isoline of $\left(v^{\prime 2}-w^{\prime 2}\right)$ is located around the channel central line and extended to about $60 \%$ of the total flow depth. However, at the border between the entrance slope and the deep pool, the zero isoline of $\left(v^{\prime 2}-w^{\prime 2}\right)$ is limited to the middle of flow depth and near the channel central line. Results show that in the deep pool, zero isoline of $\left(v^{\prime 2}-w^{\prime 2}\right)$ moves away from central line toward the channel walls and locates in the middle of flow depth. Along the accelerating flow section of the pool-riffle sequence, the zero isoline of $\left(v^{\prime 2}-w^{\prime 2}\right)$ covers a small region and is located near the channel bed. As showed in Figures $8 \mathrm{a}$ and $8 \mathrm{f}$ that zero isoline of $\left(v^{\prime 2}-w^{\prime 2}\right)$ and the negative values of $\left(v^{\prime 2}-w^{\prime 2}\right)$ disappear along both the upstream riffle and downstream riffle.

\section{Conclusions}

Results showed that for the 3D pool riffle sequence, the near-bed velocity decreases and increases along convective deceleration flow (CDF) and convective acceleration flow (CAF), respectively. Along the $2 \mathrm{D}$ pool riffle sequence, the near-bed velocity also decreases and increases along $\mathrm{CDF}$ and $\mathrm{CAF}$, respectively, but have larger values than those for the 3D pool riffle sequence. Along the 3D pool riffle sequence, flow separation has not been observed 
582 away from the channel wall, flow separation has been observed. Additionally, the length of 583 the flow separation zone increases up to the distance of $30 \mathrm{~cm}$ from the channel wall, and then decreased toward the channel central line ( $45 \mathrm{~cm}$ from the channel wall). It means the longest flow separation length is occurred along the longitudinal line of $30 \mathrm{~cm}$ away from the channel wall. It is found that the shear velocities estimated from the slope of the velocity gradient in the inner layer $\left(u^{*}{ }_{i n}\right)$, decreases in the CDF section, and increases in the CAF section at any distances from the channel wall in the 3D pool riffle sequences.

Investigation of shear stress profiles showed that, for normal flow in both 2D and 3D pool riffle sequences, shear stress near channel bed has the highest value and linearly decreased to zero at water surface. Also, for flow in the 3D pool riffle sequence, the Reynolds shear stress is highest at the CDF section along longitudinal lines with distances of $10 \mathrm{~cm}$ and $20 \mathrm{~cm}$ away from the channel wall; however, for distances of $30 \mathrm{~cm}$ and $45 \mathrm{~cm}$ away from the channel wall, the highest shear stress moves toward the deep pool. For flow in the 2D pool riffle sequence, the highest shear stress moves toward the channel central line in the deep pool. At the end of the exit slope of pool, the shape of the shear stress profile is still affected from the CAF section. For flow in the entrance slope section and deep pool, the shear velocities estimated from turbulence intensities is higher than those estimated from timeaveraged velocities. However, for flow in the exit slope section of the pool riffle sequence, values of $u_{i n}^{*}$ are higher than $u_{R}^{*}$. Despite the irregularities, the higher values $u_{R \max }^{*}$ occur in the deep pool and decreased toward both upstream riffle and downstream riffle. The values of $u_{t k e}^{*}$ indicates that shear stresses calculated from all three components of turbulence $\left(u_{t k e}^{*}\right)$, are higher than shear stresses calculated from Reynolds stress $\left(u_{R}^{*}\right)$ along the channel section of

Analyses of secondary flow in both 2D and 3D pool riffle sequences have been conducted. It is found that $m_{l}$ is the dominant coefficient which has the highest fluctuation. The absolute values of $\mathrm{M}_{13}$ along the channel central line showed that, along the entrance slope of the pool riffle sequence, the intensity increased in the flow direction, the intensity was constant and the largest in the deep pool, and decreased along the exit slope. From these results, one can

612 say that secondary currents along the decelerating flow section indicated convergence of flow 613 along the channel central line. In contrast of the decelerating flow section, divergence of flow 614 along the central line channel in the accelerating flow section has been observed. Our 
615 findings confirmed the results of MacVicar and Rennie (2012). Also near the channel wall, 616 secondary flow and divergence rotated counter-clockwise.

617

618 For flow in the 2D pool riffle sequence, assessment of distribution of production term of 619 secondary currents showed that zones with low values of production term are near the 620 channel wall in the upstream riffle section and are located near the channel bed in the 621 entrance slope. While zones with high values of production term appear around the channel 622 central line. In contrast, for flow in the 3D pool-riffle sequence, zones with low values of 623 production term in the upstream riffle are located at water surface along the channel central 624 line. For flow in the decelerating flow section, a zone of approximately $10 \mathrm{~cm}$ wide contains 625 negative and zero values is located near the channel central line. In this section zones with 626 high values are observed near the channel wall. In the deep pool zone with low values of 627 production term of secondary current still remains around the channel central line.

\section{References}

631 1) Afzalimehr, H., and Anctil, F. 2001, Friction velocity associated to a nonuniform flow 632 and an intermediate scale roughness, J. Hydraul. Res., 39(2), 181-186.

633 2) Best, J. 2005, The fluid dynamics of river dunes: A review and some future research 634 directions, J. Geophys. Res., 110(F4), F04S02, doi:10.1029/2004JF000218.

635 3) Best, J., and Kostaschuk, R. A. 2002, An experimental study of turbulent flow over a 636 low-angle dune, J. Geophys. Res., 107(C9), 3135, doi:10.1029/ 2000JC000294.

637 4) Biron, P. M., Robson, C., Lapointe, M. F., and Gaskin, S. J. 2004, Comparing different 638 methods of bed shear stress estimates in simple and complex flow fields, Earth Surf. 639 Processes Landforms, 29, 1403-1415.

640 5) Booker, D. J., Sear, D. A., and Payne, A. J. 2001, Modelling threedimensional flow 641 structures and patterns of boundary shear stress in a natural pool-riffle sequence, Earth $642 \quad$ Surf. Processes Landforms, 26, 553- 576.

643 6) Carling, P. A., and Orr, H. G. 2000, Morphology of riffle-pool sequences in the River 644 Severn, England, Earth Surf. Processes Landforms, 25, 369-384.

645 7) Clifford, N. J. 1996, Morphology and stage-dependent flow structure in a gravel-bed 646 river, in Coherent Flow Structures in Open Channels, edited by P. J. Ashworth et al., 647 pp. 545-566, John Wiley, Wallingford, U. K. 
648 8) Clifford, N. J., and Richards, K. S. 1992, The reversal hypothesis and the maintenance 649 of riffle-pool sequences: A review and field appraisal, in Lowland Floodplain Rivers: 650 Geomorphological Perspectives, edited by P. Carling and G. E. Petts, pp. 43- 70, John 651 Wiley, Chichester, U. K.

652 9) Einstein, H. A. and Li, H. 1958. Secondary currents in straight channels. Am. Geophys. 653 Union Trans., Vol. 39, pp. 1085-1088.

654 10) Fazlollahi, A., Afzalimeh, H., Sui, J., 2015b. Effect of slope angle of an artificial pool 655 distributions of turbulence. Int. J. sed. Res. 30(2), 93-99, DOI: $656 \quad 10.1016 /$ j.ijsrc.2015.03.008.

657 11) Gerard, R. 1978, Secondary How in Noncircular Conduits, J. Hydraulics Div., ASCE, Vol. 104, No. HY5. pp. 755-773.

12) Goring, D. G., and Nikora, V. I. 2002, Despiking Acoustic Doppler Velocimeter data, J. Hydraul. Eng., 128(1), 117-126.

13) Grigoriadis, D. G. E., Balaras, E., and Dimas, A. A. 2009, Large-eddy simulations of unidirectional water flow over dunes, J. Geophys. Res., 114, F02022, doi:10.1029/2008JF001014.

14) Hassan, M., and Woodsmith, R. D. 2004, Bedload transport in an obstruction- formed pool in a forest gravelbed stream, Geomorphology, 58, 203-221.

15) Karcz I. 1966, Secondary currents and the configuration of a natural stream bed. J Geophys Res. ;71:3109-16.

16) Keller, E. A. 1971, Areal sorting of bed material: The hypothesis of velocity reversal, Geol. Soc. Am. Bull., 83, 915-918.

17) Krogstad, P. Å., Skâre,P. E. 1995, Influence of a strong adverse pressure gradient on the turbulent structure in a boundary layer, Physics of Fluids, 7(8), 2014-2024.

18) Lee, J., Lee, J. H., and Sung, H. J. 2010, Coherent structures in turbulent boundary layers with adverse pressure gradients, J. Turbul., 11, 1-20.

19) Lee, J. H., and Sung H. J. 2009, Structures in turbulent boundary layers subjected to adverse pressure gradient, J. Fluid Mech., 639, 101-131.

20) Liu, C., Shan, Y.Q., Yang, K.J., and Liu, X.N. 2013. The characteristics of secondary flows in compound channels with vegetated floodplains, J. Hydrodynamics, 25(3), 422429. DOI:10.1016/S1001-6058(11)60381-9.

21) MacVicar, B. J., and Rennie, C. D. 2012, Flow and turbulence redistribution in a straight artificial pool, Water Resour. Res., 48, W02503, doi:10.1029/2010WR009374. 
22) MacVicar, B. J., and Roy, A. G. 2007a, Hydrodynamics of a forced riffle pool in a gravel bed river: 1. Mean velocity and turbulence intensity, Water Resour. Res., 43, W12401, doi:10.1029/2006WR005272.

23) MacVicar, B. J., and Roy, A. G. 2007b, Hydrodynamics of a forced riffle pool in a gravel bed river: 2. Scale and structure of coherent turbulent events, Water Resour. Res., 43, W12402, doi:10.1029/2006WR005274.

24) MacWilliams, M. L., Wheaton, Jr., J. M., Pasternack, G. B., Street, R. L., and Kitanidis, P. K. 2006, Flow convergence routing hypothesis for poolriffle maintenance in alluvial rivers, Water Resour. Res., 42, W10427, doi:10.1029/2005WR004391.

25) Müller A, Studerus X. 1979, Secondary flow in an open channel. In: Proceedings of the 18th IAHR congress, Cagliari, Italy, vol. 3, p. 19-24.

26) Nezu, I. and Nakagawa, H. 1984, Cellular Secondary Currents in Straight Conduit, J. Hydraulic Eng., ASCE, Vol. 110, No. 2. pp. 173-193.

27) Nezu, I., and Nakagawa, H. 1993, Turbulence in Open-Channel Flows, 281 pp., A.A. Balkema, Rotterdam, Netherlands.

28) Nezu, I, Nakagawa, H, Kawashima, N. 1988, Cellular secondary currents and sand ribbons in fluvial channel flows. In: Proceedings of the $6^{\text {th }}$ congress of APD-IAHR, Kyoto, Japan, 2(1), p. 51-8.

29) Onitsuka, K., Akiyama, J., and Matsuoka, S. 2009, Prediction of velocity profiles and Reynolds stress distributions in turbulent open-channel flows with adverse pressure gradient, J. Hydraul. Res., 47(1), 58-65.

30) Onitsuka, K.; Nezu, I. 2001, Generation mechanism of turbulence driven secondary currents in open-channel flows. In IUTAM Symposium on Geometry and Statistics of Turbulence; Kluwer Academic: Boston, MA, USA.

31) Radhakrishnan, S., Piomelli, U., Keating, A., and Lopes, A. S. 2006, Reynoldsaveraged and large-eddy simulations of turbulent non-equilibrium flows, J. Turbul., 7, $1-30$.

32) Sawyer, A. M., Pasternack, G. B., Moir, H. J., and Fulton, A. A. 2010, Riffle-pool maintenance and flow convergence routing observed on a large gravel-bed river, Geomorphology, 114(3), 143-160.

33) Song, T., and Chiew, Y. M. 2001, Turbulence measurement in nonuniform openchannel flow using acoustic doppler velocimeter (ADV), J. Eng. Mech., 127(3), 219231. 
714

715

716

717

718

719

720

721

34) Thompson, D. M. 2002, Channel-bed scour with high versus low deflectors, J. Hydraul. Eng., 128, 640- 643.

35) Thompson, D. M. 2004, The influence of pool length on local turbulence production and energy slope: A flume experiment, Earth Surf. Processes Landforms, 29, 13411358.

36) Thompson, D. M. 2006, The role of vortex shedding in the scour of pools, Adv. Water Resour., 29, 121-129.

37) Thompson, D. M. 2007, The characteristics of turbulence in a shear zone downstream of a channel constriction in a coarse-grained forced pool, Geomorpholgy, 83, 199- 214.

38) Thompson, D. M., Wohl, E. E., and Jarrett, R. D. 1996, A revised velocityreversal and sediment-sorting model for a high-gradient, pool-riffle stream, Phys. Geogr., 17, 142156.

39) Thompson, D. M., and Wohl, E. E. 2009, The linkage between velocity patterns and sediment entrainment in a forced-pool and riffle unit, Earth Surf. Processes Landforms, 34, 177-192.

40) Venditti, J. G. 2007, Turbulent flow and drag over fixed two- and threedimensional dunes, J. Geophys. Res., 112, F04008, doi:10.1029/ 2006JF000650.

41) Wang, Z.Q., Cheng, N.S. 2006, Time-mean structure of secondary flows in open channel with longitudinal bedforms, Advances in Water Resources, 29(11), PP. 16341649.

42) Wang, Z.Q., Cheng, N.S., Chiew, Y.M, Chen XW. 2003 Secondary flows in open channel with smooth and rough bed stripes. In: Proceedings of the 30th IAHR congress, Thessaloniki, Greece, C(1), p. 111-8.

43) Wang, Z.Q., Cheng, N.S., Chiew, Y.M. 2004, Measurement of secondary flow over a longitudinally ridged bed. In: Second international conference on scouring and erosion (ICSE-2), Singapore, B, p. 391-8.

44) Wang, Z.Q., Cheng, N.S. 2005, Secondary flows over artificial strips. Adv Water Resour, 28, 441-50.

45) Warnack, D. and Fernholz, H. 1998, The effect of favorable pressure-gradient and of the Reynolds number on an incompressible axisymmetric turbulent boundary layer, Part 1. The boundary layer with relaminarization, J. Fluid Mech., 359, 329-356.

46) Webster, D. R., DeGraaff, D. B., and Eaton, J. K. 1996, Turbulence characteristics of a boundary layer over a two-dimensional bump, J. Fluid Mech., 320, 53-69.

47) White, F.W. 1991, Viscous Fluid Flow. $2^{\text {nd }}$ ed. McGraw-Hill, New York. 
758

759

760

48) Wilkinson, S. N., Keller, R. J., and Rutherfurd, I. D. 2004, Phase-shifts in shear stress as an explanation for the maintenance of pool-riffle sequences, Earth Surf. Processes Landforms, 29, 737- 753.

49) Yang, S. Q., and Chow, A. T. 2008, Turbulence structures in non-uniform flows, Adv. Water Resour., 31(10), 1344-1351.

50) Yang, S.-Q., Yu, J.X., and Wang, Y.-Z. 2004, Estimation of diffusion coefficients, lateral shear stress, and velocity in open channels with complex geometry, Water Resour. Res., 40, W05202, doi:10.1029/2003WR002818.

(a)

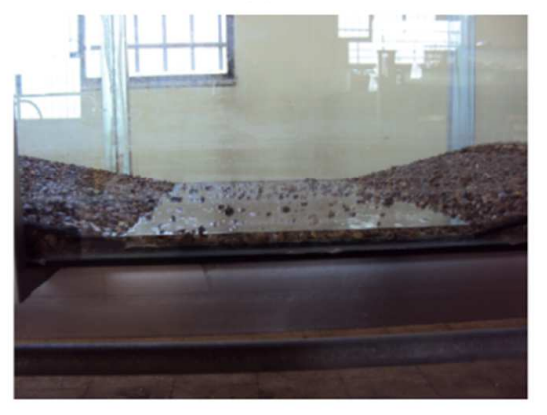

(b)
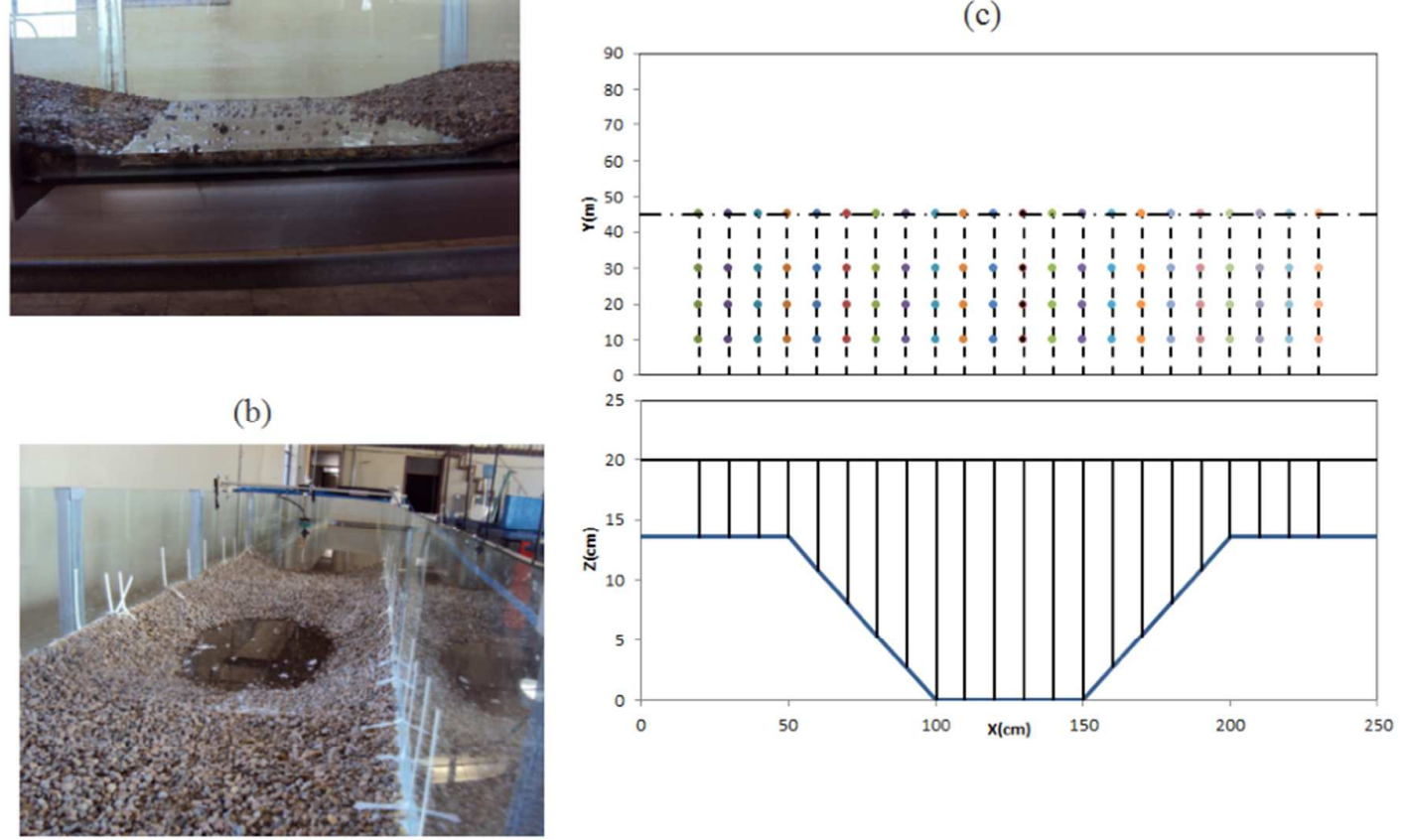

Figure 1: (a) Two dimensional (2D) pool riffle; (b) three dimensional (3D) pool riffle; (c) 

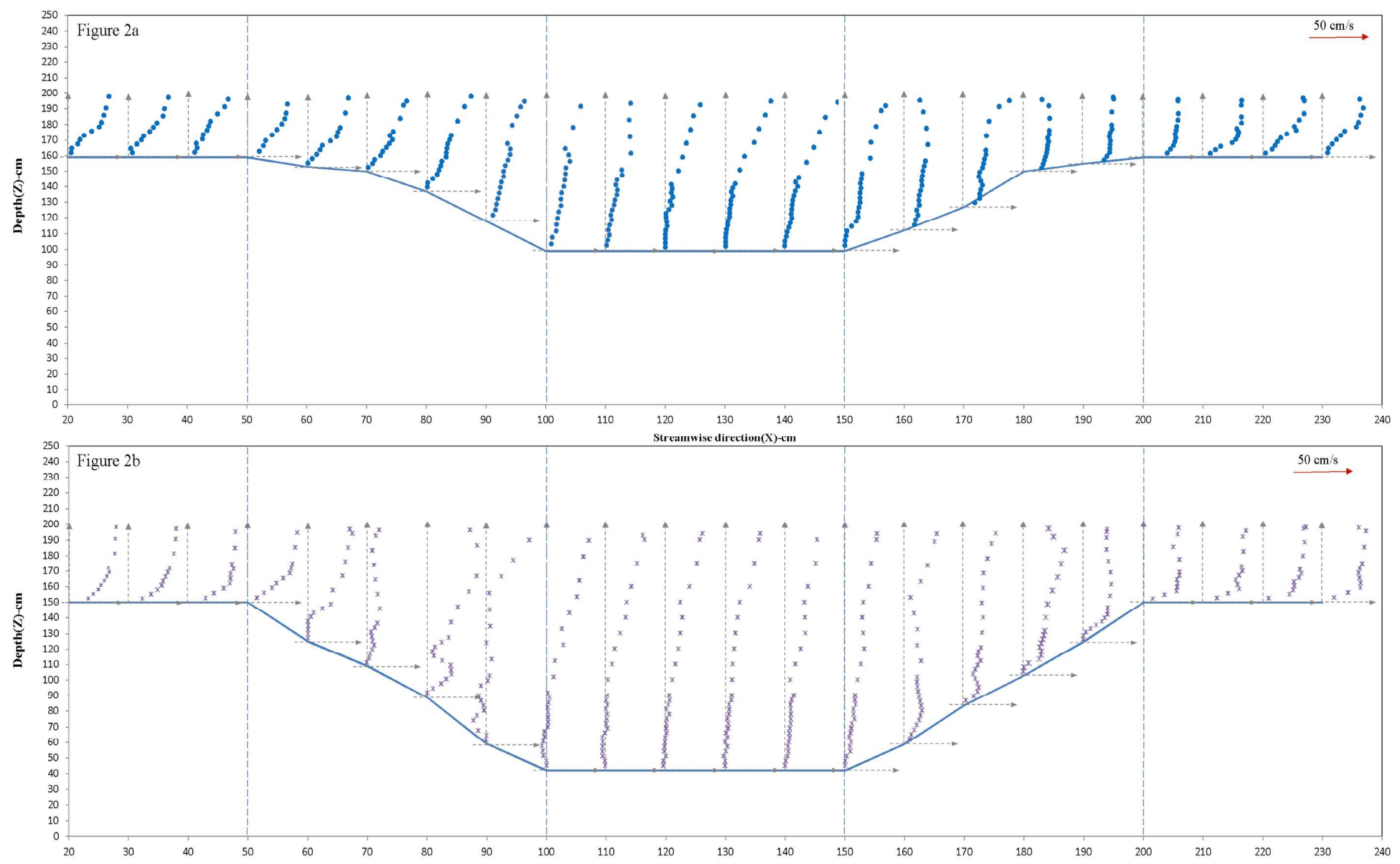

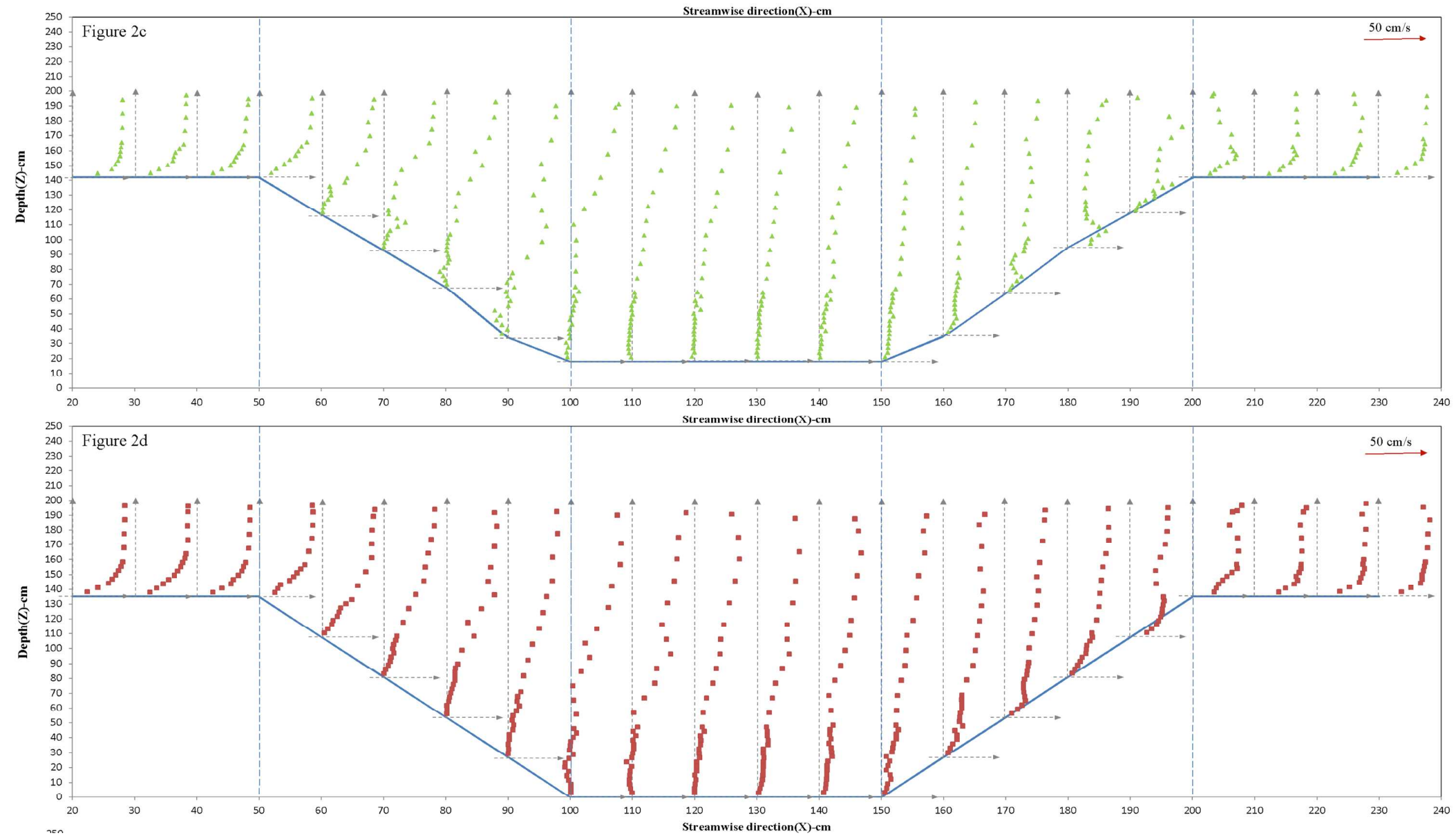

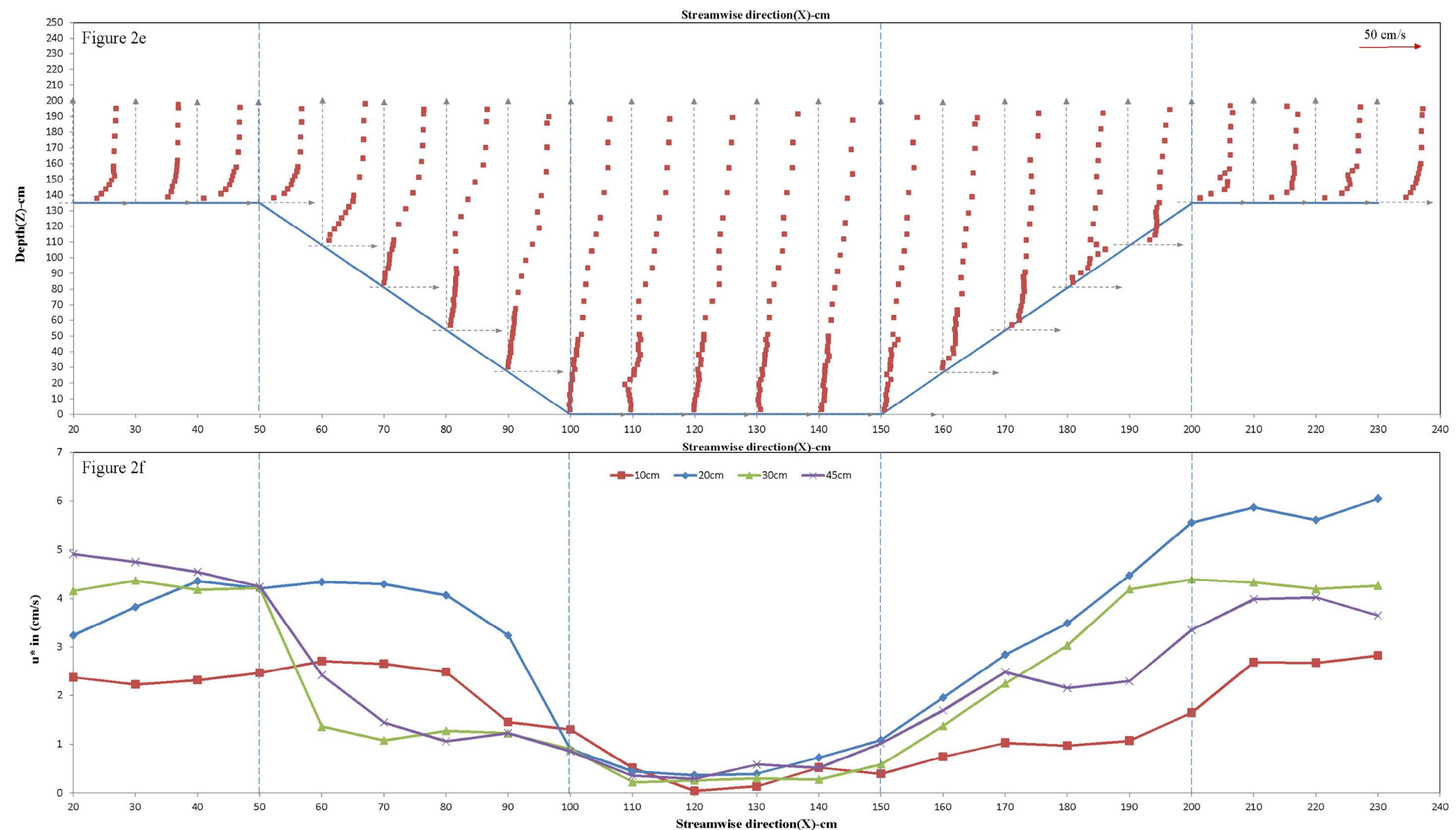

Figure 2. $(\mathrm{a}-\mathrm{d})$ Streamwise velocity profiles along the channel, for distances $10 \mathrm{~cm}, 20 \mathrm{~cm}, 30 \mathrm{~cm}$ and $45 \mathrm{~cm}$ away from channel wall for $3 \mathrm{D}$ pool riffle, respectively; (e) streamwise velocity at a distance $45 \mathrm{~cm}$ (central line) away from channel wall for 2D pool riffle; (f) trend of shear velocity $\left(u^{*}{ }_{i n}\right)$ 

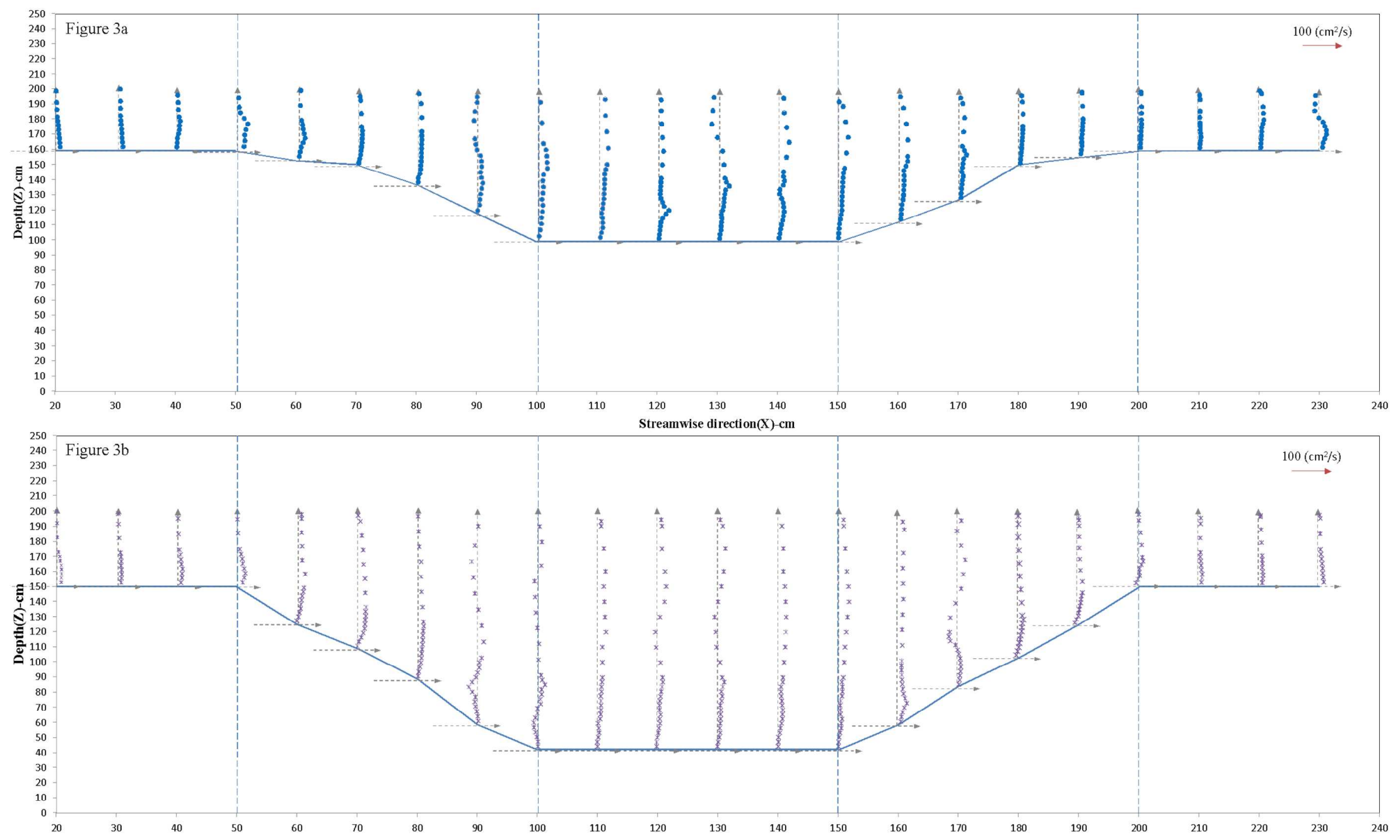

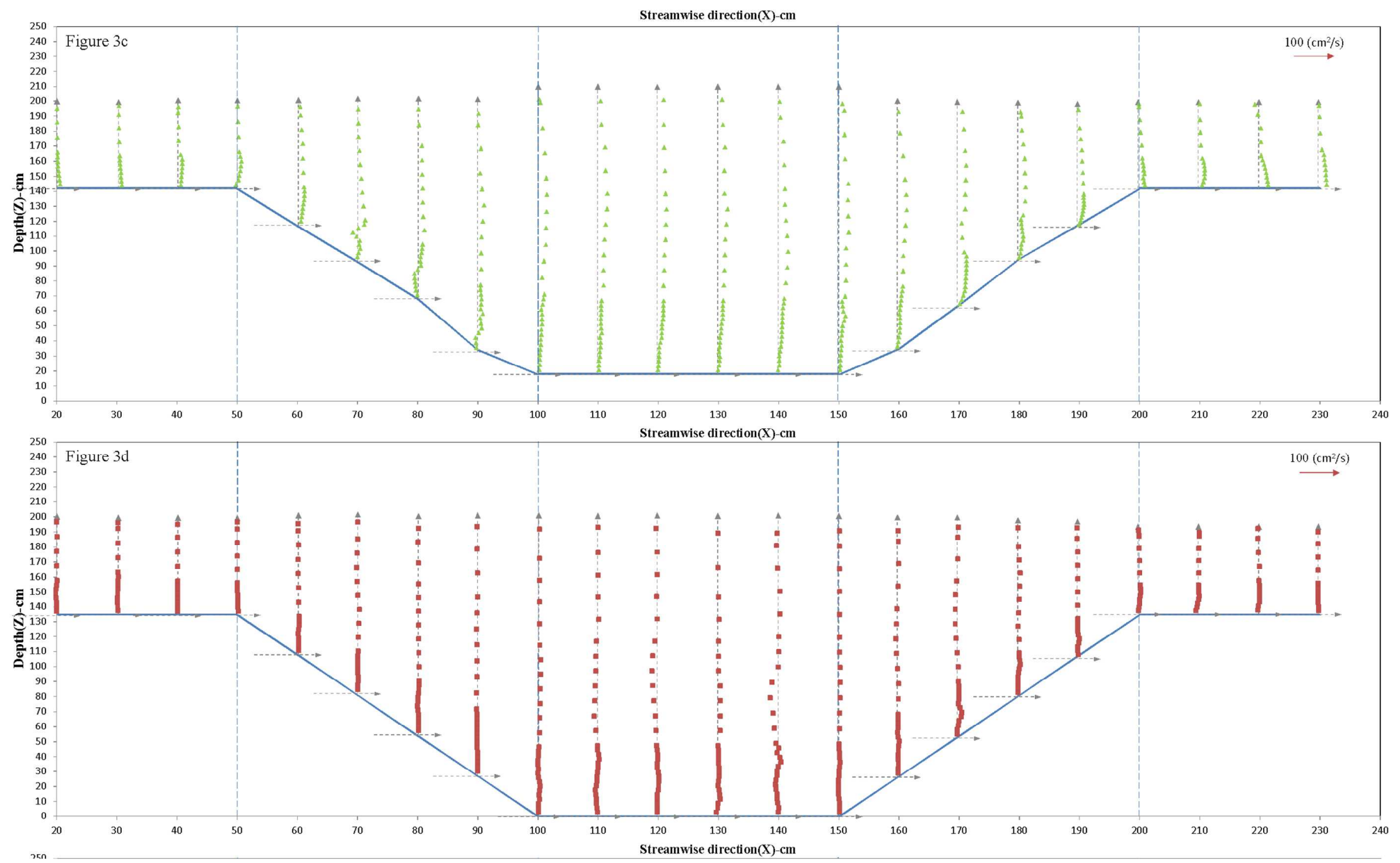

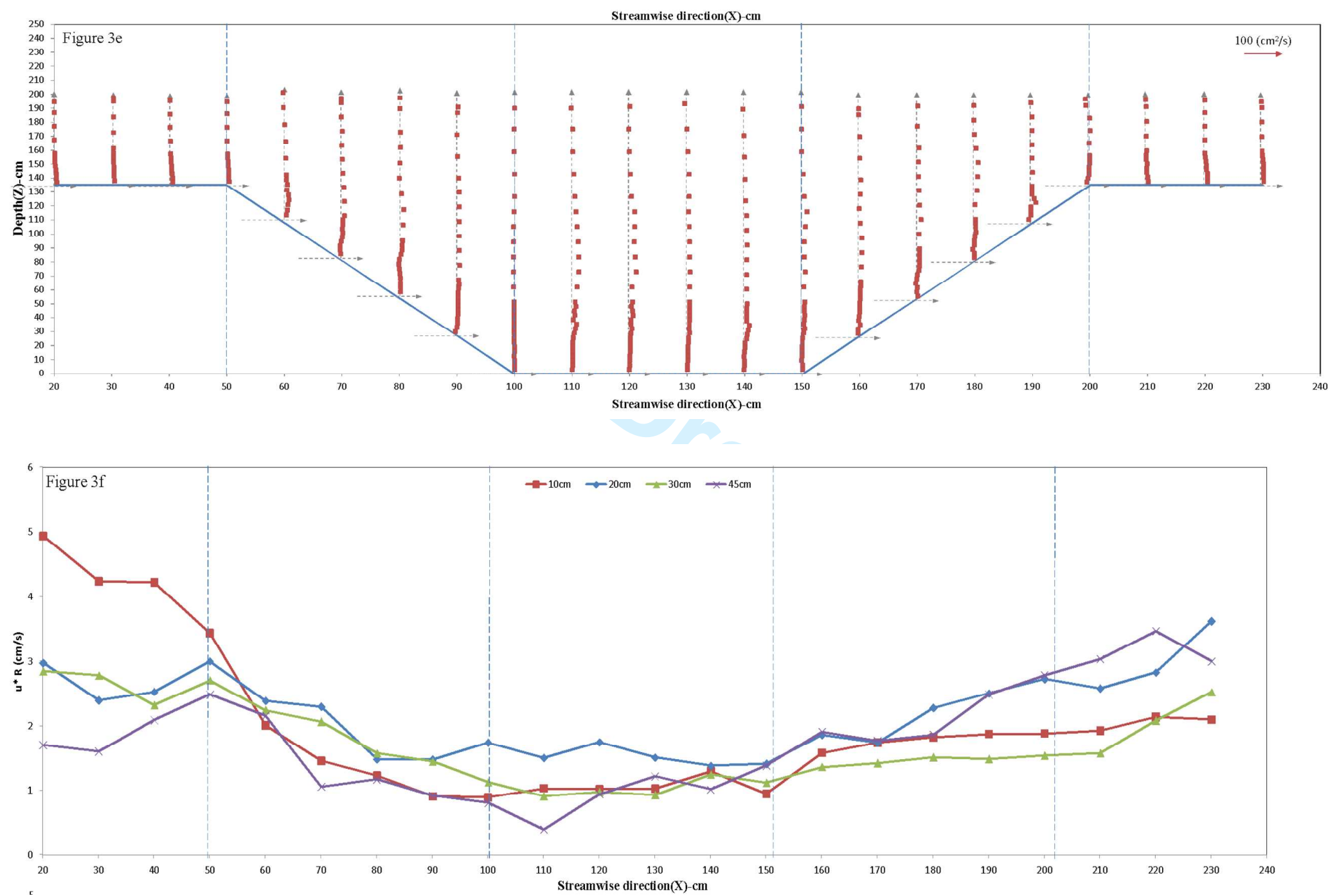

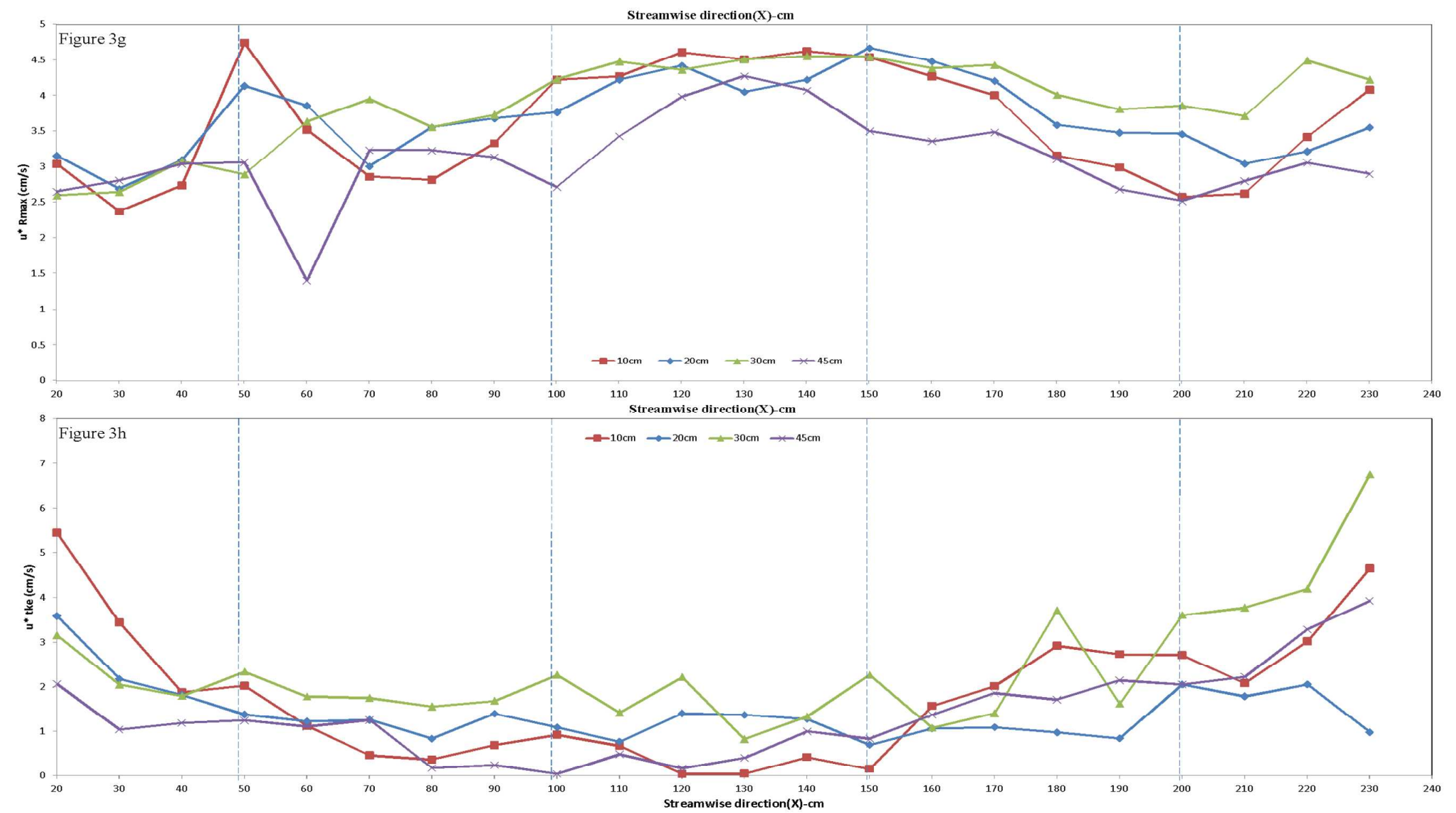

Figure 3: (a-d) Reynolds shear stress profiles along the channel, for distances of $10 \mathrm{~cm}, 20 \mathrm{~cm}, 30 \mathrm{~cm}$ and $45 \mathrm{~cm}$ away from the left channel wall, respectively; (e) shear stress at a distance $45 \mathrm{~cm}$ (central line) away from channel wall for 2D pool riffle; (f) trend of shear velocity $\left(u^{*}\right)$; (g) trend of shear velocity $\left(u_{R \max }\right)$; (h) trend of shear velocity $\left(u_{R}^{*}\right)$ 


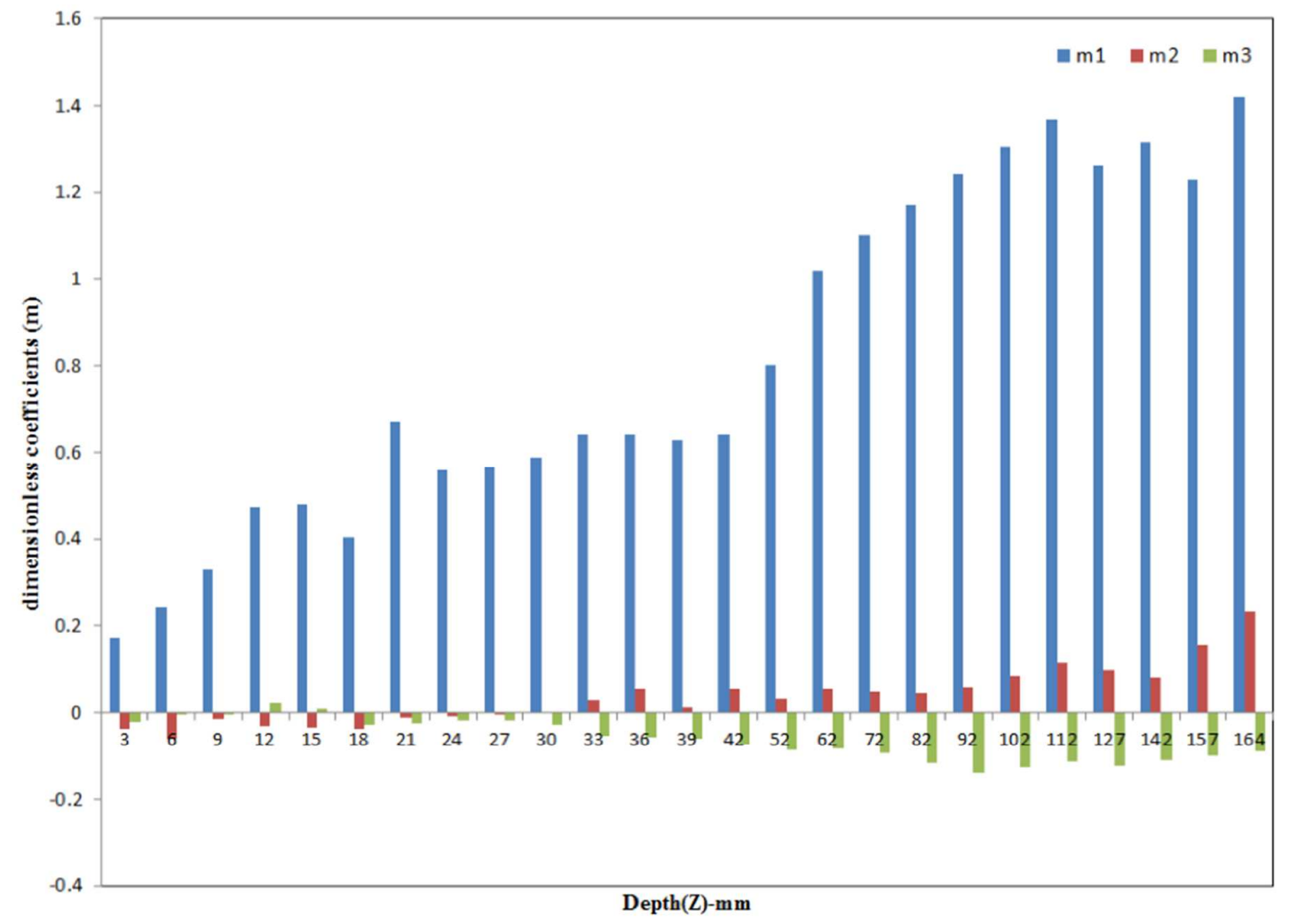

Figure 4 An example of dimensionless coefficients for 3D pool riffle sequence 


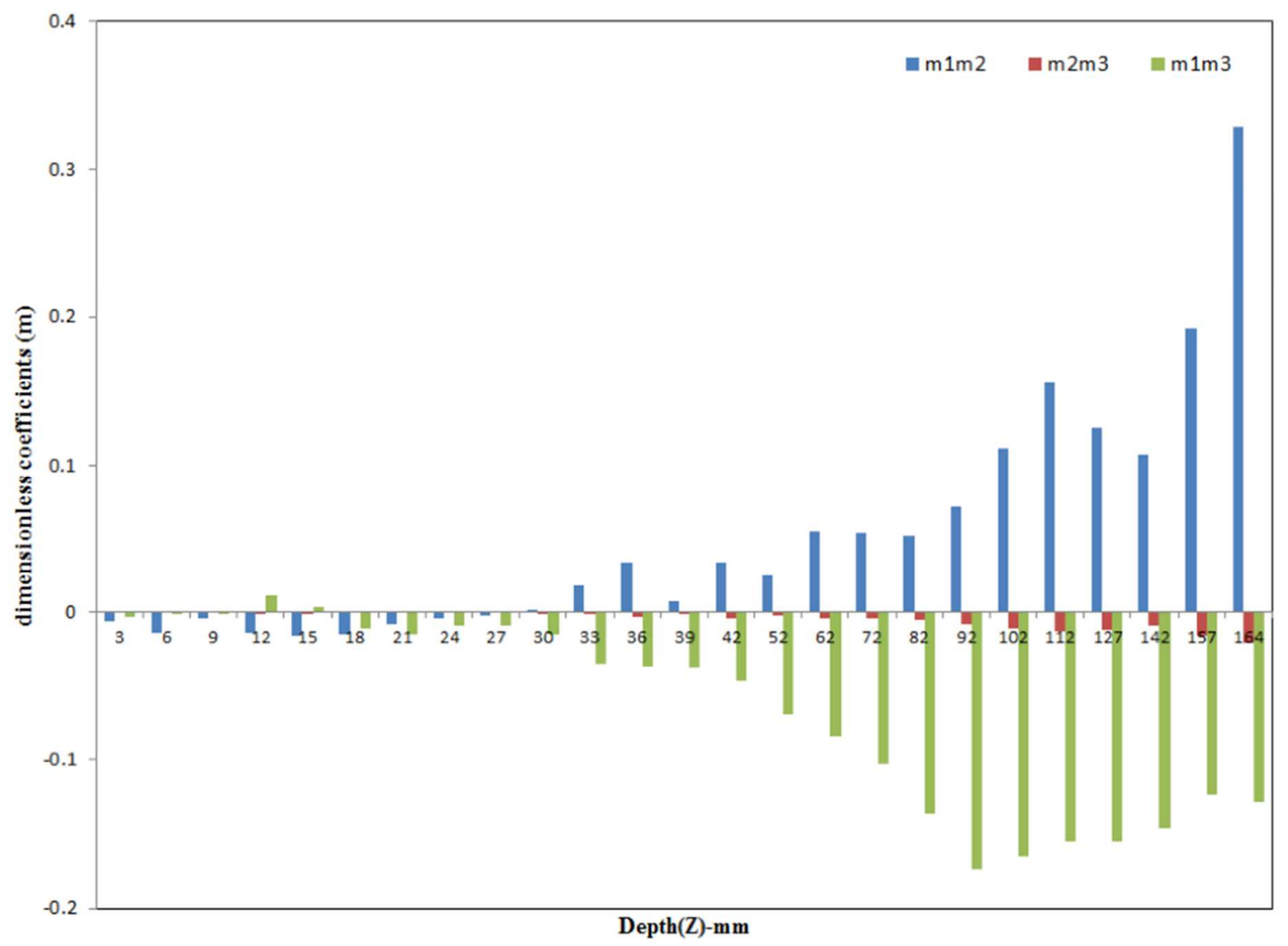

Figure 5 An example of multiplied of dimensionless coefficients for 3D pool riffle sequence 

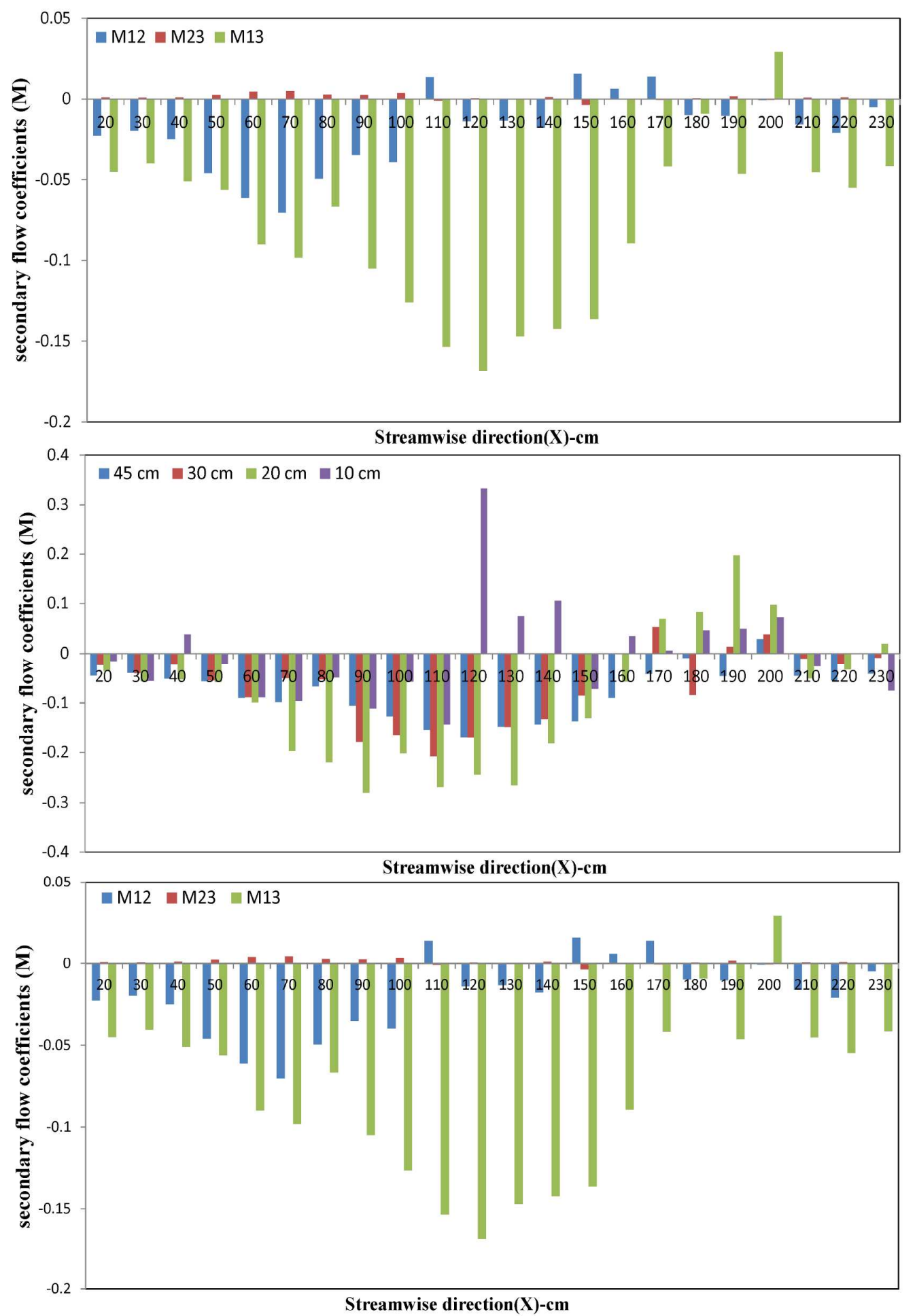

Figure 6: (a) Absolute M-values along the stream direction at the center line for 3D pool riffle; (b) M13 absolute values along the stream direction for four different distances from channel wall for 3D pool riffle; (c) Absolute M-values along the stream direction at the center line for $2 \mathrm{D}$ pool riffle; 

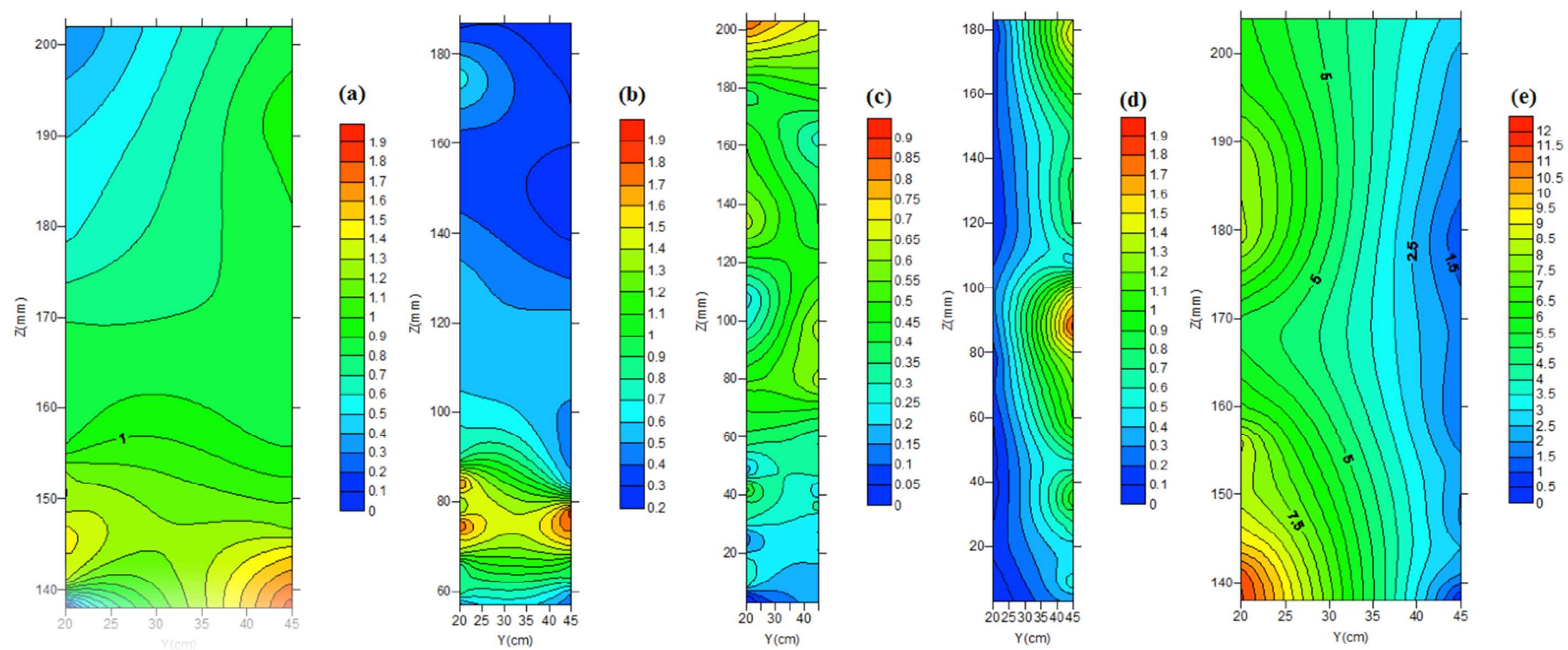

Figure 7: Distribution of $\left(v^{, 2}-w^{2}\right)$ for 3D pool riffle sequence: (a) upstream riffle; (b) decelerating section; (c) deep pool; (d) accelerating section; (e) downstream riffle 

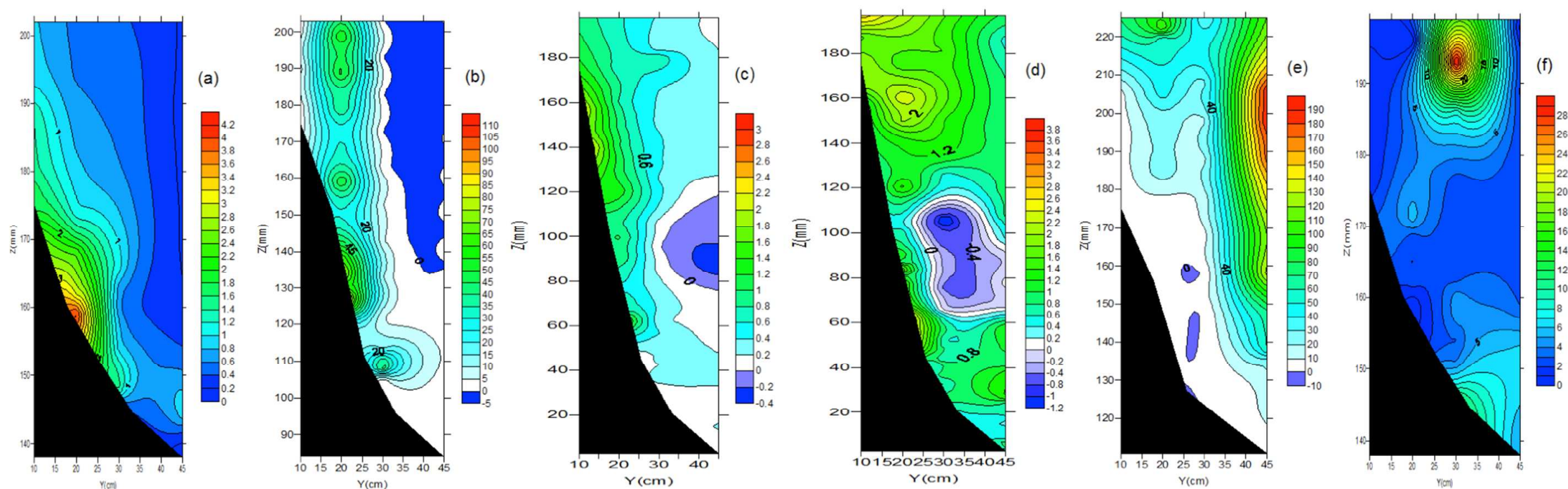

Figure 8. Distribution of $\left(v^{2}-w^{2}\right)$ for 3D pool riffle sequence: (a) upstream riffle; (b) decelerating section; (c) boundary between entering slope and the deep pool; (d) at the pool toward the accelerating section; (e) accelerating section; (f) downstream riffle 